\title{
WestVirginiaUniversity
}

THE RESEARCH REPOSITORY @ WVU

Graduate Theses, Dissertations, and Problem Reports

2017

\section{Study of stress anisotropy on shale rock permeability}

Charbel Nasr

Follow this and additional works at: https://researchrepository.wvu.edu/etd

\section{Recommended Citation}

Nasr, Charbel, "Study of stress anisotropy on shale rock permeability" (2017). Graduate Theses,

Dissertations, and Problem Reports. 4011.

https://researchrepository.wvu.edu/etd/4011

This Problem/Project Report is protected by copyright and/or related rights. It has been brought to you by the The Research Repository @WVU with permission from the rights-holder(s). You are free to use this Problem/Project Report in any way that is permitted by the copyright and related rights legislation that applies to your use. For other uses you must obtain permission from the rights-holder(s) directly, unless additional rights are indicated by a Creative Commons license in the record and/ or on the work itself. This Problem/Project Report has been accepted for inclusion in WVU Graduate Theses, Dissertations, and Problem Reports collection by an authorized administrator of The Research Repository @ WVU. For more information, please contact researchrepository@mail.wvu.edu. 


\title{
STUDY OF STRESS ANISOTROPY ON SHALE ROCK PERMEABILITY
}

\author{
CHARBEL NASR
}

\author{
Problem Report submitted to the \\ College of Engineering and Mineral Resources \\ At West Virginia University \\ In partial fulfillment of the requirements \\ for the degree of
}

Master of Science

in

Petroleum and Natural Gas

\author{
Sam Ameri, Prof. Committee Chairperson \\ Ming Gu, Ph.D. Research Advisor \\ Kashy Aminian, Ph.D. Academic Advisor
}

Department of Petroleum and Natural Gas Engineering

Morgantown, West Virginia

2017

Keywords: Anisotropy, In situ stress state

Copyright 2017 Charbel Nasr 


\section{ABSTRACT \\ Study of Stress Anisotropy on Shale Rock Permeability}

Charbel Nasr

Permeability is one of the most time-consuming rock petro-physical properties to measure, especially in the case of shales and tight rocks with Micro-Darcy ranges. Several unsteady state methods like GRI, Pressure Pulse Decay (PPD) have been applied to measure permeability but unfortunately results are not accurate due to the limitations to in situ stress conditions, repeatability and reproducibility issues. To overcome this limitations a system under steady state condition and with equal confining and axial pressure has been developed, obtaining remarkable permeability measurements. This system was designed and assembled by Zamirian et al 2015 referred to as Precision Petrophysical Analysis Laboratory (PPAL).

Shale reservoirs are heterogeneous, anisotropic and are subject to in-situ stress state. In-situ stresses are divided into overburden pressures $\left(\delta_{v}\right)$, maximum $\left(\delta_{H}\right)$ and minimum horizontal stresses $\left(\delta_{h}\right)$ which are usually different in magnitude. Stress dependent permeability plays an important role since it contributes to the gas transport throughout the matrix, natural fractures and hydraulic fractures. A test has been done using the PPAL system, but still has stress limitations since the axial and confining stress applied to the core sample are equal, unlike the in situ stress conditions. Because of that, this research introduces the methodology of using a Triaxial core holder in the PPAL system (T-PPAL) in order to understand how stress anisotropy affects permeability.

Two cases will be studied, using T-PPAL, the first case is to measure vertical permeability $\left(K_{v}\right)$, (when the core plug is vertically drilled) under in situ-stress state, where axial stress $\left(\delta_{v}\right)$ is larger than confining stress $\left(\delta_{h}\right)$. The second case is to measure horizontal permeability $\left(K_{h}\right)$, (when the core plug is horizontally drilled) at different horizontal stress anisotropies defined as the ratio of maximum over minimum horizontal stress $\left(\delta_{H} / \delta_{h}\right)$. The tri-axial test designed for PPAL will provide a better understanding of how stress anisotropy affects shale rock permeability. 


\section{DEDICATION}

To my team, my wife Krystel Morales, my son Charbel and daughter Nicole, without them this project we decided to start would never have been done. Their support, patience and constant sacrifice gives me the strength and motivation to achieve all my goals.

To my parents who taught me the best values in life, I want to thank them for their support, sacrifice and love they have given me.

To my siblings and friends, whose support has always motivated me and inspire me. 


\section{ACKNOWLEDGMENT}

I gratefully acknowledge the support and guidance of my committee members of the Petroleum and Natural Gas department, most particularly my research advisor Dr. Ming Gu, whose support, and constant supervision during my program helped me finish my research. I also appreciate the opportunity that was given to me as research assistant. Definitely Dr. Ming Gu's knowledge in unconventional reservoir will add value to the Department.

I also would like to express my sincere appreciations to my academic advisor and member of my committee Dr. Kashy Aminian, for his support and guidance since the first day I stepped in at West Virginia University. Throughout his valuable advising, I learned and accomplished my studies successfully.

Sincerely, I would like to express my deepest gratitude to Professor Sam Ameri Department Chair, for his encouragement, support, motivation and guidance during my research and career. Thank you so much, for make me feel at home, without your help this Master would never have taken shape.

My thanks also go out to the faculties Dr. Ali Takbiri, Dr. Mehrdad Zamirian, the students Amir Ansari and Mohamed Elsaig for their valuable contribution during my research. 


\section{TABLE OF CONTENTS}

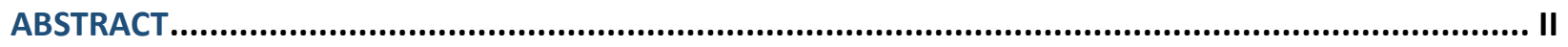

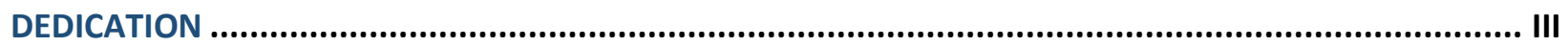

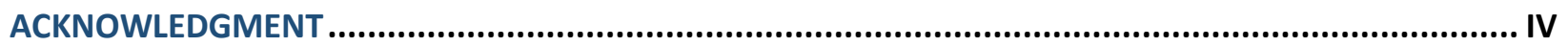

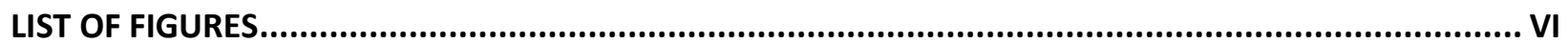

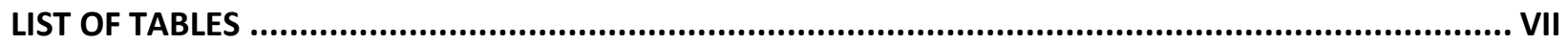

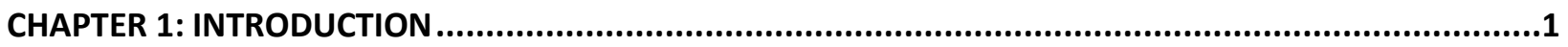

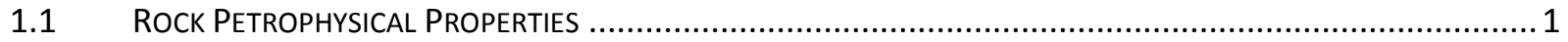

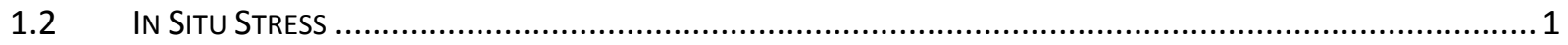

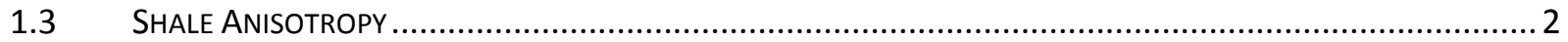

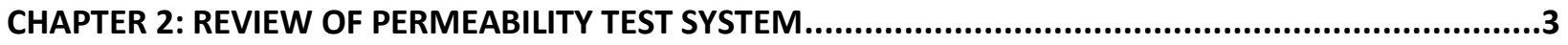

2.1 OVERVIEW OF THE LIMITATIONS OF PAST SHALE PERMEABILITY TESTS.......................................... 3

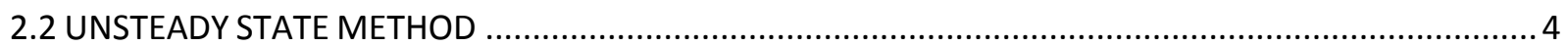

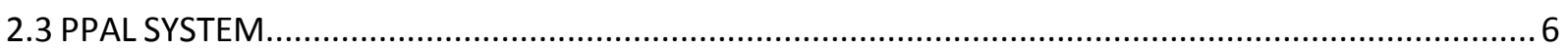

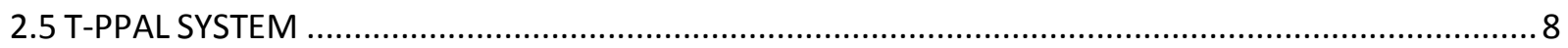

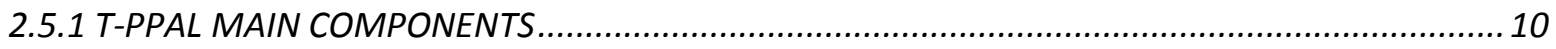

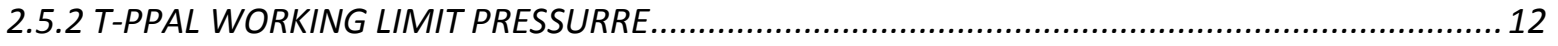

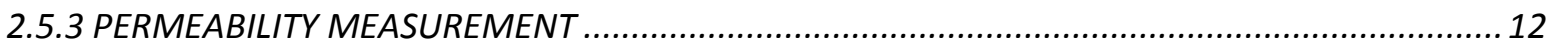

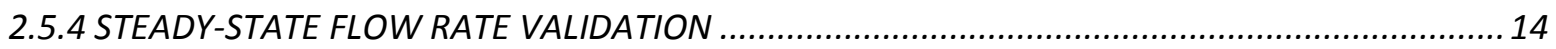

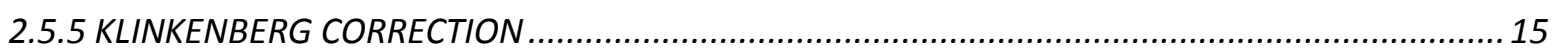

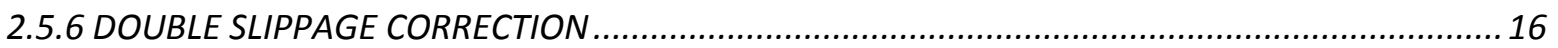

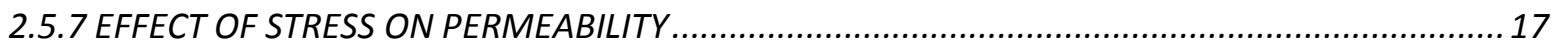

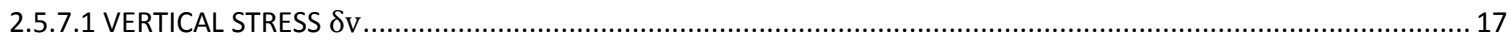

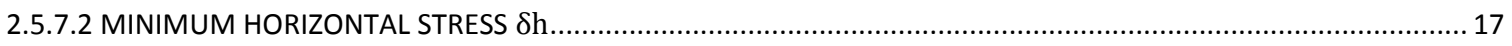

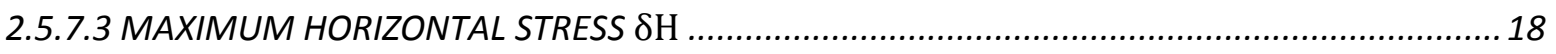

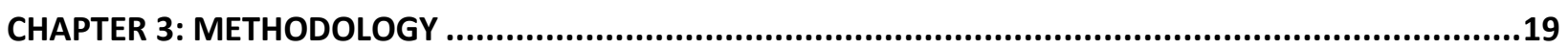

3.1 METHODOLOGY TO MEASURE PERMEABILITY WITH EQUAL CONFINING AND AXIAL PRESSURE

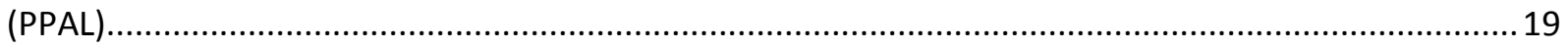

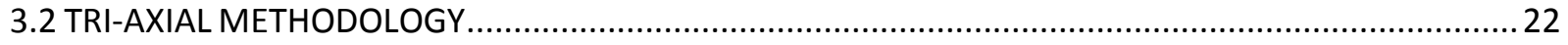

3.2.1 T-PPAL TEST PROCEDURE

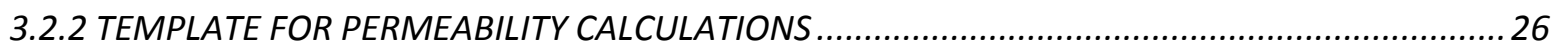

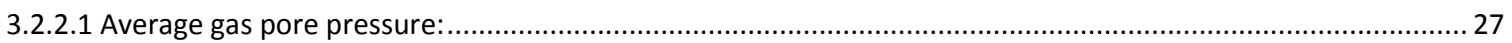

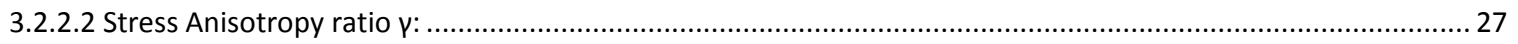

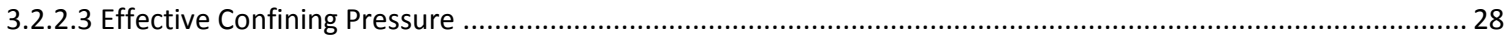

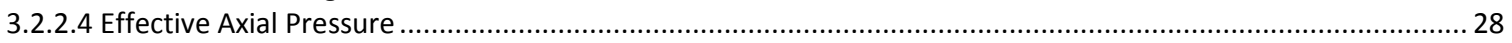

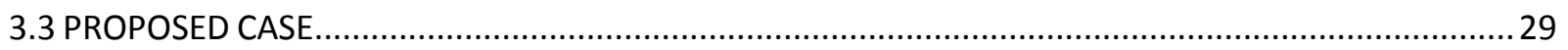

3.3.1 CASE 1 VERTICALLY DRILLED CORE SAMPLE

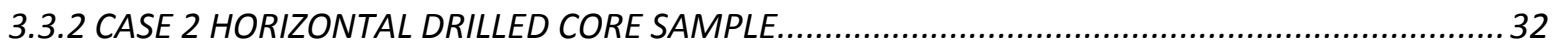

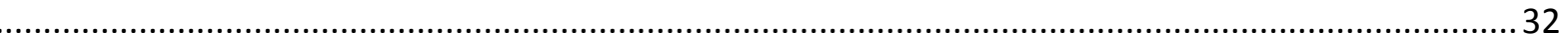

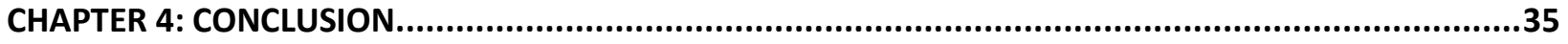

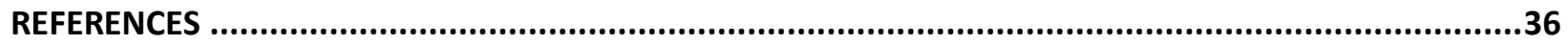




\section{LIST OF FIGURES}

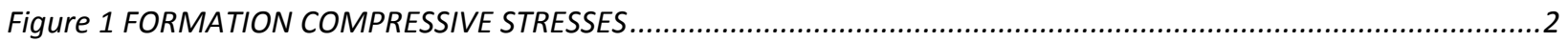

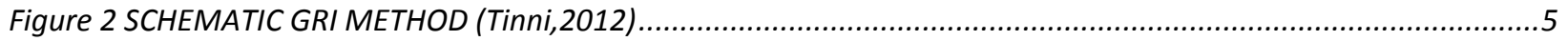

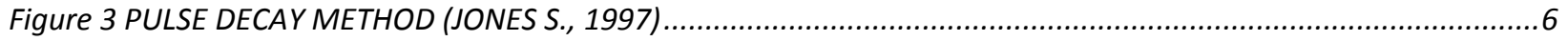

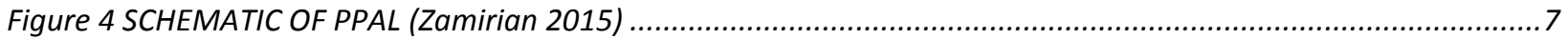

Figure 5 T-PPAL CORE HOLDER (CORE HOLDER MANUFACTURER MANUAL)....................................................

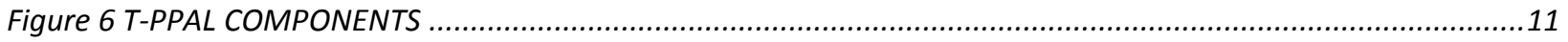

Figure 7 DARCY'S LAW REPRESENTATION ..............................................................................................15

Figure 8 ABSOLUTE PERMEABILITY Vs PORE PRESSURE EFFECT (MODIFIED FROM ZAMIRIAN ET AL., 2015).............21

Figure 9 EFFECT OF NET STRESS IN ABSOLUTE PERMEABILITY MODIFIED FROM ZAMIRIAN ET AL., 2015) ................21

Figure 10 GEOMECHANICAL EFFECT ON PERMEABILITY MODIFIED FROM ZAMIRIAN ET AL., 2015).......................22

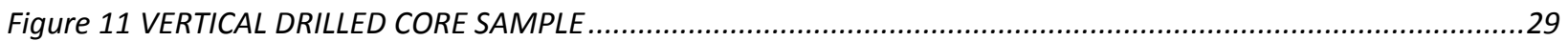

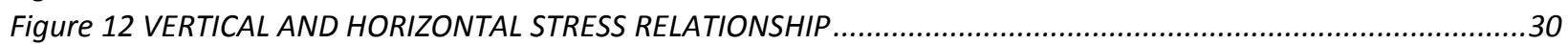

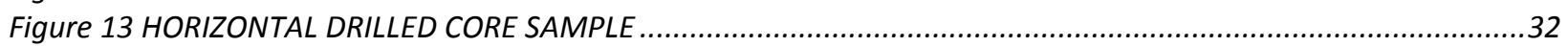

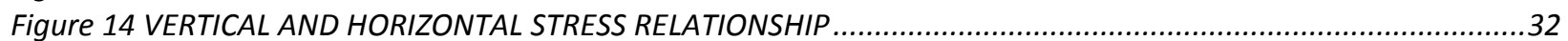




\section{LIST OF TABLES}

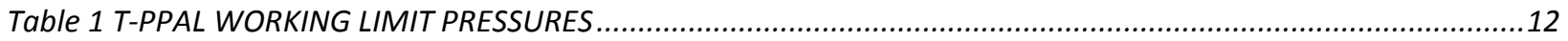

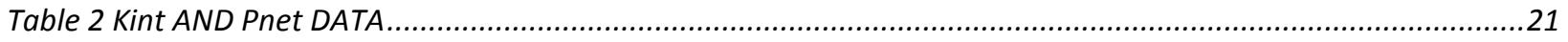

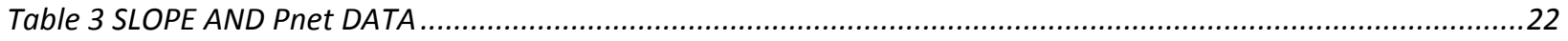

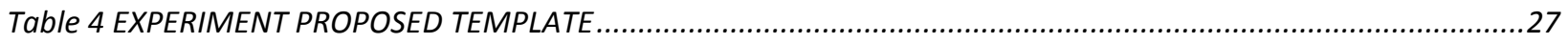

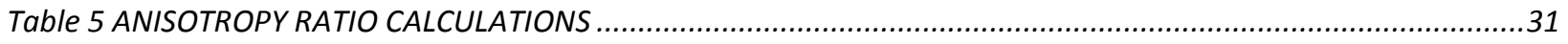

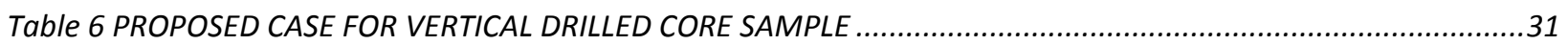

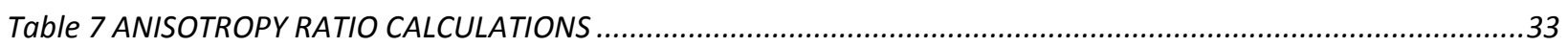

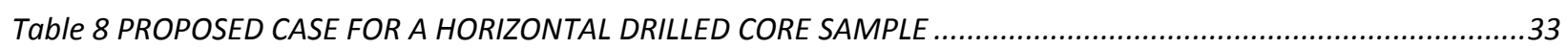




\section{CHAPTER 1: INTRODUCTION}

\subsection{Rock Petrophysical Properties}

In the oil and gas industry, the development of shale gas reservoirs, has increased in the last decade due to horizontal drilling and hydraulic fracturing technology, which provides the opportunity to produce gas where previously was impossible due to low permeability formations and high costs of production.

The life of a reservoir, production wise, is a big challenge that we face in the energy industry and the petrophysical property of rock such as porosity and permeability in gas shale reservoirs plays an important role relative to predict production; permeability is been defined as one of the most important property in order to control and predict the reservoir performance, however, it is the most difficult to measure since the characteristics of shale are ultra-low permeability (Nano Darcy to micro Darcy), heterogeneous and anisotropic.

\subsection{In Situ Stress}

In-situ stress is important for reservoir flow capacity determination, because shale matrix pore structure, natural fractures and layer boundaries are all highly impacted by stress anisotropy and stress magnitude. In situ stress condition, is hard to simulate in lab and the core sample shape plays an important role to perform the permeability measurements. Ideally, permeability measurements should be done using a core sample in cubic geometry to apply the stress the same way the formation is subject to it, but the core samples commonly used in core flooding have cylindrical geometry which makes it more difficult to apply the stress in axial and horizontal direction.

Deep formations are under compressional stresses, which can be classified into three principal stresses, the overburden stress, minimum and maximum horizontal stress (Fig.1). Such stresses are compressive and anisotropic, which means that the compressive stresses on the rock have different magnitudes at different directions. 


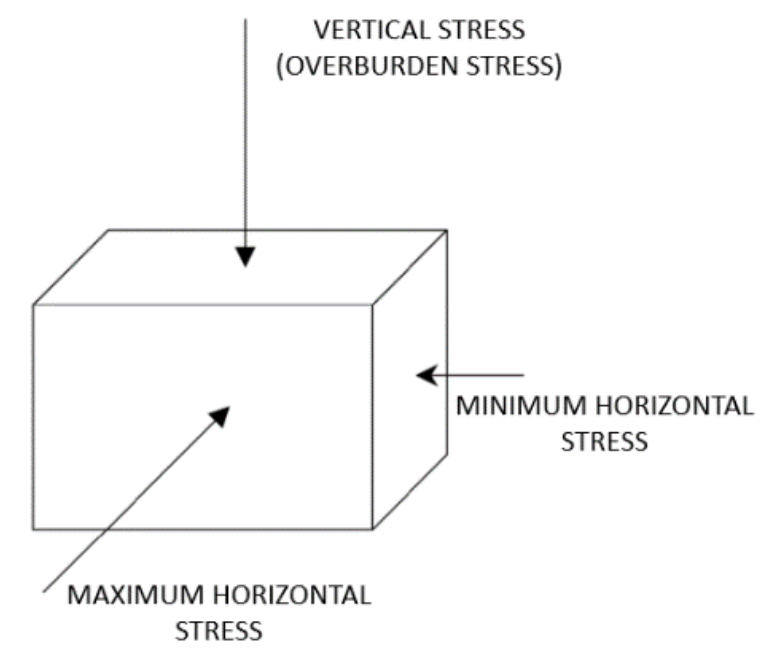

Figure 1 FORMATION COMPRESSIVE STRESSES

\subsection{Shale Anisotropy}

Shales are usually heterogeneous and anisotropic, advance understanding of this characteristic is fundamental in order to determine the impact of shale stress on permeability. Measurements of the shale petrophysical properties in shales is challenging since rock properties changes in different directions. Shale gas reservoirs behaves as a dual porosity/permeability system in which matrix, natural fractures, and hydraulic fractures contribute to gas transport. These systems are subjected to in-situ stresses arising from the combined effects of overburden pressures, tectonic stresses and pore pressure. It is vital to understand the importance of stress on shale rock permeability because the economic viability of shale gas developments heavily relay on sustaining sufficient fracture conductivity in hydraulic and it is extremely difficult to maintain high fracture conductivity due to proppant embedment and proppant crushing. (Fan et al., 2010, Gu et al., 2016). 


\section{CHAPTER 2: REVIEW OF PERMEABILITY TEST SYSTEM}

The objective of this research is to design a methodology to perform permeability measurements under in-situ stress condition using a tri-axial system. The benefit of performing laboratory experiments using this system is that the core sample will be subject to independent magnitudes of confining stress and axial stress. For example, for a vertically drilled core sample, the confining stress can be used to simulate average horizontal stress while the axial stress is used to simulate vertical overburden stress. For a horizontally drilled core sample, the confining stress is used to simulate one horizontal stress while the axial stress is used to simulate the other horizontal stress at orthogonal direction.

\subsection{OVERVIEW OF THE LIMITATIONS OF PAST SHALE PERMEABILITY TESTS}

Determination of rock petrophysical properties in shale reservoirs, has been a challenge due to the ultra-low porosity and permeability. The quantification of these properties are key to better understand the performance of a shale reservoir. To determine some parameters such as Original gas in place, production rates and optimize the hydraulic fracturing treatments in unconventional reservoirs, is essential to have reliable results rock petrophysical properties such as permeability, porosity and adsorption characteristics under reservoir conditions.

Shale is an organic-rich, naturally fractured formation with ultra-low matrix permeability. Similar to conventional hydrocarbon systems, unconventional reservoirs are characterized by complex geological and petrophysical system as well as heterogeneities at all scales. However, unlike conventional reservoirs, shales typically have very fine grain rock texture, exhibit gas storage and flow characteristics which are uniquely tied to Nano-scale pore throat and pore size distribution and possess common organic and clay content that serve as gas sorption sites. (Council, A primer. na, 2009). Besides, natural fractures contribute to flow also, which highly increase the apparent permeability of the bulk shale rock (Gu et al., 2016, Zamirian et al., 2015). 
It is not practical to measure permeability of the shale core samples by the conventional laboratory steady state technique due to the following limitations:

$>$ Extremely low flow rates.

$>$ Ultra-low permeability values in Nano-scale range.

$>$ Period of time required to reach the steady state condition.

Simulate the in-situ stress condition.

Consequently, Laboratory investigations using unsteady state methods to measure permeability have been done, such as GRI and pulse decay. These methods have been put forward as alternative investigative tools to measure permeability in shale core samples. Both methods have tried to measure permeability in these unconventional plays but the results are questionable due to high inaccuracy. Moreover, a system has been designed and assembled (Zamirian, 2015) to study the influence of pore pressure and confining stress on permeability and porosity of shale core samples obtaining remarkable permeability measurements. However, regarding the stress, the system cannot simulate the real reservoir condition since the core sample is subject to the same confining and axial pressure. Beside aforementioned techniques, there have been some attempts to measure ultra-low permeability under steady state condition but these applications were either limited to micro-Darcy permeability range or lacked validation (Rushing et al., 2004; Carles et al., 2007; Sinha et al. 2012).

\subsection{UNSTEADY STATE METHOD}

GRI method carry out the permeability measurement on crushed rock samples. It applies a pressure pulse on unconfined crushed rock particles. Permeability is then obtained through the analysis of the pressure decay over time. This method has the advantage of shorter experimental time comparing with pressure decay method. Unfortunately, the permeability measured from crushed sample can differ by two to three orders of magnitude from companion intact sample (Passey et al., 2010; Tinni et al., 2012). 
A disadvantage of this method is that the micro cracks in the crushed particles essentially violate the GRI assumptions leading to the overestimate of permeability (Tinni et al., 2012). Despite GRI is a common, cost effective method it cannot be applied under reservoir stress conditions making it less reliable. Additionally, recent studies have shown inconsistent results such as the size of the crushed particles, incapability of measuring fracture permeability, equilibrium pressure and volume conditions of the test. Figure 2 (Tinni et al., 2012), illustrates GRI method.

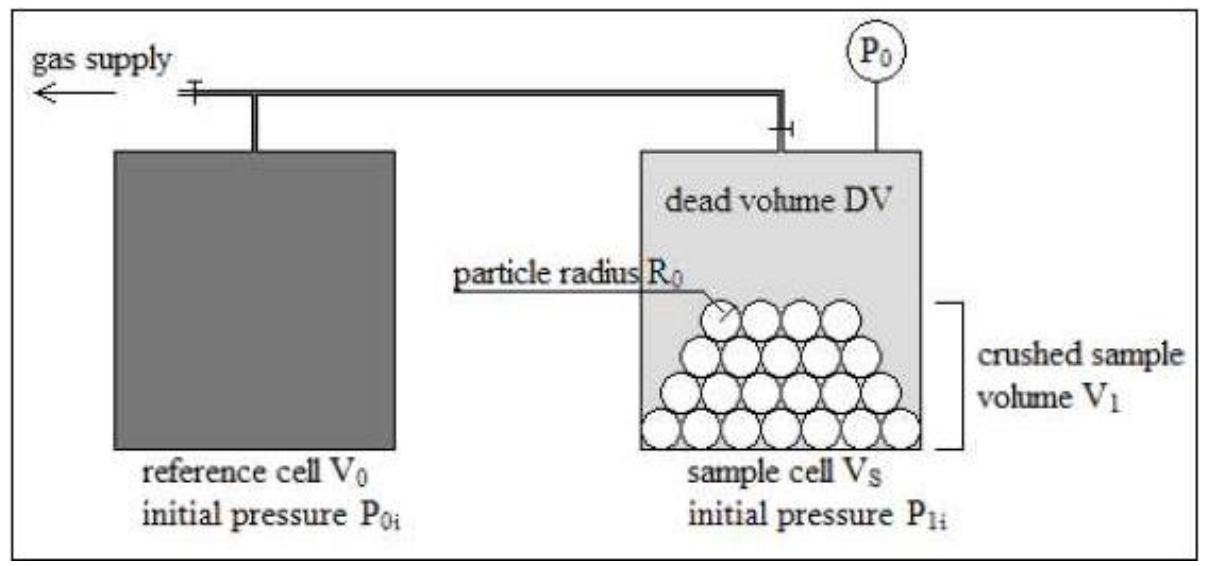

Figure 2 SCHEMATIC GRI METHOD (Tinni,2012)

The pulse decay is a transient method. When a pressure pulse is initiated at the upstream of the core plug, it starts the decay process over time. The decay characteristics depend on the permeability, dimensions of the sample, volumes of upstream and downstream reservoirs, and the fluid properties. Permeability can be estimated by analyzing the decay characteristics of a pressure pulse (Brace et al., 1968). With pulse-decay method the permeability of tight rock can be evaluated in a short period by a nondestructive manner.

One of the disadvantages is its inability to measure the high permeability rock. Furthermore, neglecting of pore volume introduces errors when permeability is calculated from the pressuredecay signals. For example, the error can be unacceptable when measuring high-porosity lowpermeability rock. Again, it is difficult to measure high permeability rock because of system limitations in controlling and detecting short duration transients. 
If different setups, for example, different upstream and downstream volumes, are used to measure the same core, the repeatability of pulse-decay method will be low because pore volume is not considered (K. Ling et al. / Journal of Natural Gas Science and Engineering 15 (2013) 1e7).

Overall, unsteady state methods such as GRI and pressure pulse decay have been used for decades to estimate permeability in Nano-Darcy range of the shale, yet the results are inaccurate. The inaccuracy of the results, can be attributed to the experimental conditions, since they are not developed under reservoir stress conditions and moreover, both methods have reproducibility issues. Figure 3 (Jones S., 1997) illustrates pulse decay method.

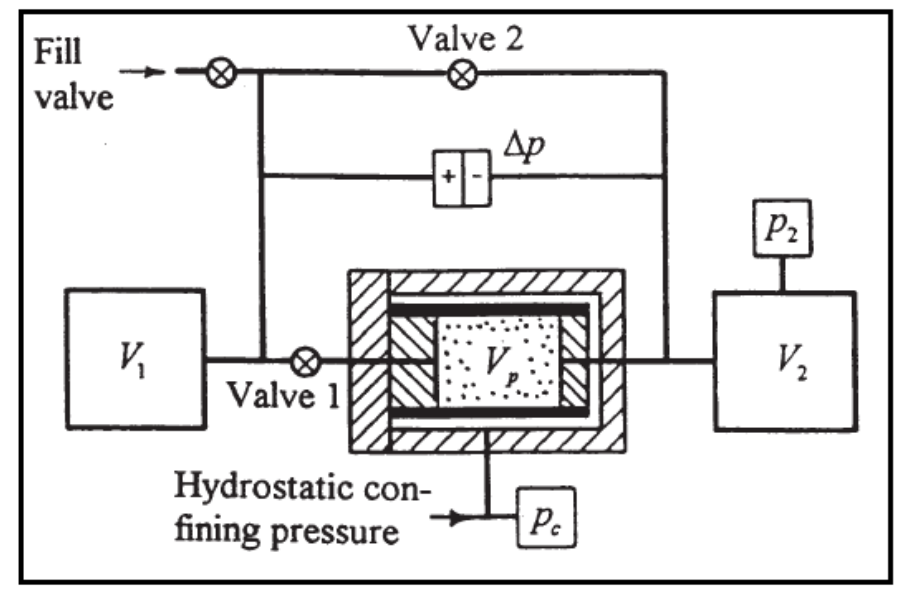

Figure 3 PULSE DECAY METHOD (JONES S., 1997)

\subsection{PPAL SYSTEM}

This system referred to as Precision Petrophysical Analysis Laboratory (PPAL), was designed and assembled by Dr. Mehrdad Zamirian (Zamirian, New Experimental Approach to Measure Petrophysical Properties of Organic-Rich Shales) and several permeability studies were done using this system (Zamirian et al, SPE-171018, Zamirian et al SPE-171613, Zamirian et al SPE174968). The design and application of the laboratory setup was assembled to test accurate and repeatable shale petrophysical properties under reservoir stress conditions. This system has been designed to study the influence of pore pressure and confining stress on permeability and 
porosity of shale core samples obtaining remarkable permeability measurements from Marcellus and Utica shale were.

PPAL is built in a closed box and modified with electric heaters, programmable temperature controller, and circulation fans to eliminate the temperature change during the experiments. It is essential to keep temperature stable because as temperature changes, pressure will significantly affected therefore, it is important to reduce temperature changes in the surrounding environment in order to achieve accurate and reliable measurement of shale rock permeability, additionally temperature can affect gas desorption/adsorption and the gas slippage effect under low pore pressure.

The PPAL frame was built with aluminum and clear Lexan to enable visibility inside the box. Moreover, all valves, such as pneumatic and electric valves, and pressure-differential transducers are automatic and controlled by a computer to eliminate any human error and to avoid any change of temperature during the experiments. PPAL is inspired from CORAL (Computer Operated Rock Analysis Laboratory), designed at the Institute of Gas Technology where it was used to measure porosity and permeability of tight sandstones of Mesaverde (Randolph, 1983). A schematic illustration of PPAL is shown in figure 4 (Zamirian 2015).

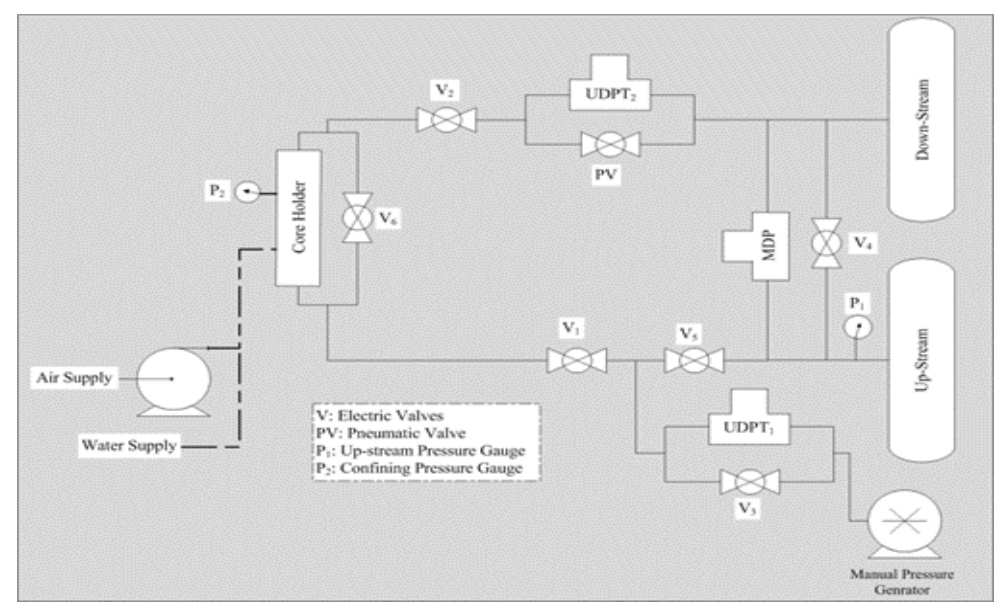

Figure 4 SCHEMATIC OF PPAL (Zamirian 2015)

Zamirian et al., (2014b) described the following PPAL advantages: 
$>$ Its valves are automatic and controlled by a computer to eliminate any human error.

$>$ Has the capabilities of simulating reservoir conditions such as pore pressure, overburden pressure, temperature and steady-state gas flow through the core plug.

Has highly accurate pressure transducers with the resolution of 0.001 psi.

$>$ Can measure the permeability with an accuracy of a Nano-Darcy and the porosity with an accuracy of $\sim 0.1 \%$.

$>$ It can provide fast, repeatable, and consistent results.

$>$ Has ability to monitor the flow rate during the experiment to know when the sample is fully saturated (adsorbed or desorbed).

It can correct the measured permeability for the pore and confining pressures.

\subsection{T-PPAL SYSTEM}

The motivation to develop this study, referred as Tri-axial Precision Petrophysical Analysis Laboratory (T-PPAL), is the complications and low repeatability issue presented in GRI, pulse decay method. Another reason why this study is proposed, is the limitation presented in both the past unsteady methods and the current PPAL system regarding the in-situ stress conditions. For unsteady state method, no stress can be applied to the sample. For current PPAL, the core sample is subject to the same confining and axial pressure, so the system cannot simulate the in-situ stress state.

Among the systems mentioned above, the PPAL system shows excellent performance of permeability measurements, and yet has a limitation relative to stress because the magnitudes of both radial and axial stress are the same. In contrast tri-axial system will solve this limitation since different stress magnitudes are applied in radial and axial direction. Therefore, the in-situ stress state can be simulated in a better way. 
Tri-axial is defined as having independent radial and axial loading. Tri-axial experiments are routinely used for gas permeability and porosity measurements. The core sample is held within a rubber sleeve by confining or radial pressure. The radial pressure simulates reservoir overburden pressures. Independent axial pressure is also applied via a floating distribution plug. Inlet and outlet distribution plugs allow fluids and gases to be injected through the core sample.

In the PPAL system, the core sample is subject to equal confining and axial stress. The stress is applied by water that is injected into the core holder and press the rubber sleeve where the core sample is inserted. In the tri-axial system, the configuration for the vertical stress (overburden stress) is the same as the PPAL system and axial stress (horizontal stress) is applied by injected water that pushes a movable chamber into the upstream end of the core sample. Figure 5 (core holder manufacturer manual) illustrates how the radial and axial stress is applied to the core sample.

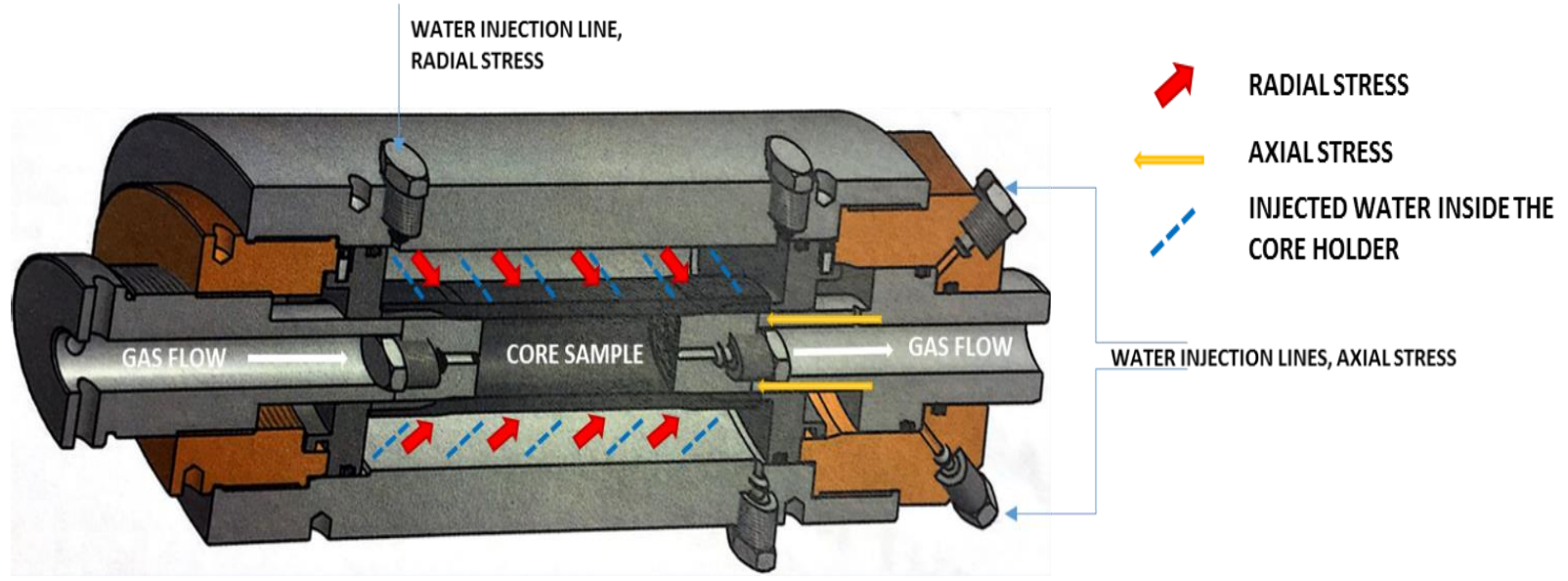

Figure 5 T-PPAL CORE HOLDER (CORE HOLDER MANUFACTURER MANUAL) 


\subsubsection{T-PPAL MAIN COMPONENTS}

A full view of the T-PPAL and main components are shown in figure 6.

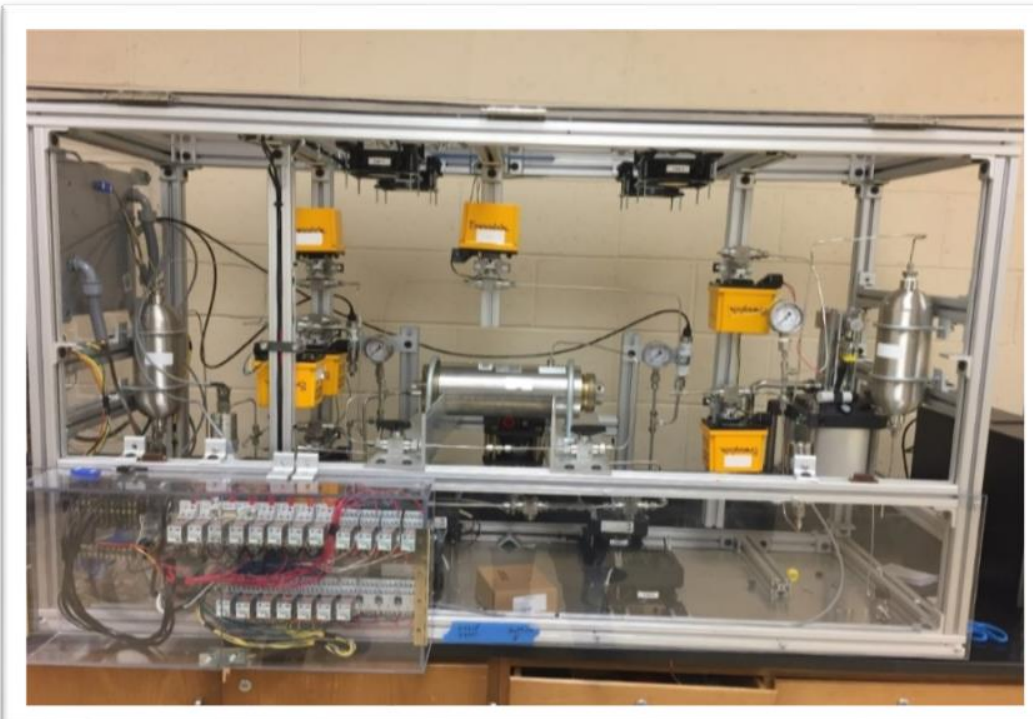

(A)

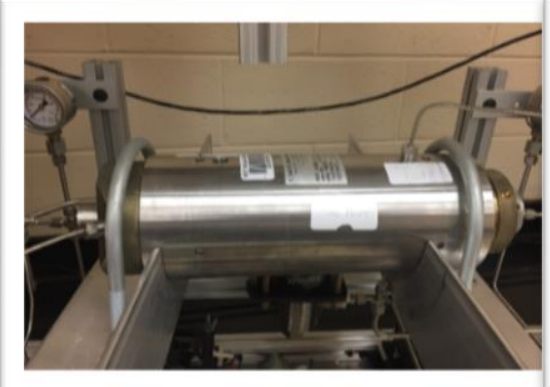

(B)

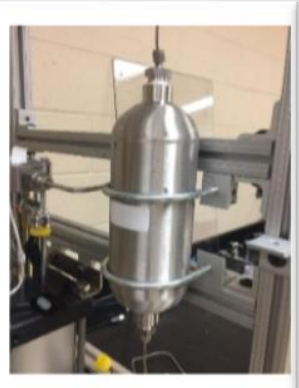

(C)

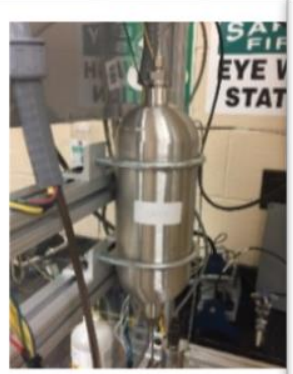

(D)

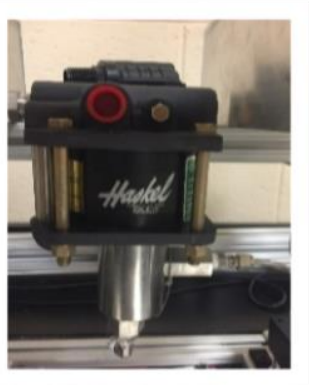

(E)

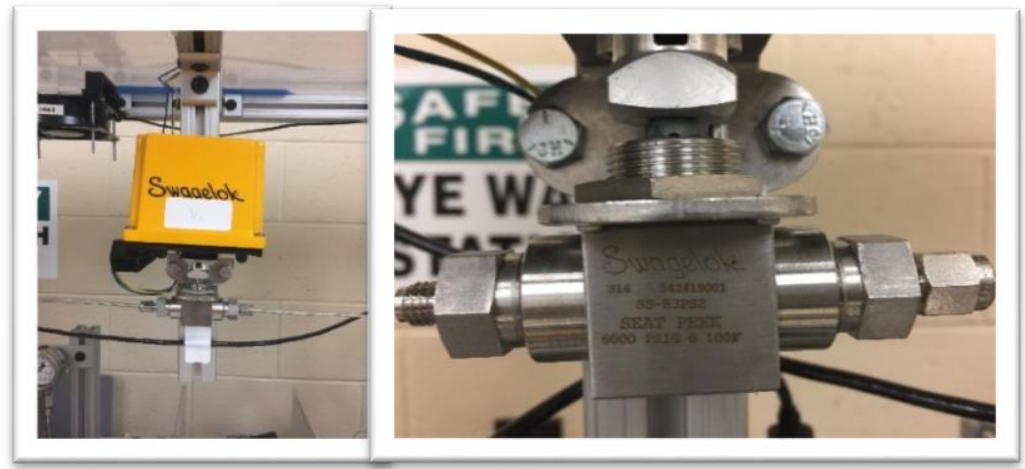

(F) 
Descriptions for the main components of T-PPAL system are provided below:

(A) The full view of the T-PPAL SYSTEM.

(B) CORE HOLDER: The core holder is a solid stainless steel instrument positioned in the center of the unit. However, it allows the unit to be heated evenly and maintains a constant and steady temperature. The core holder holds plugs with a diameter of one inch and length from one to three inches. The core sample is placed in the rubber sleeve, which is made of Viton Synthetic Elastomer to separate the sample from the injected water.

(C) - (D) TWO ONE-GALLON GAS TANKS: The tanks act as gas storage, connected to the upstream and downstream end of the core which injects the fluid at a steady level maintaining the pressure constant through the core. The downstream end of the core is connected to an Ultra-precise differential-pressure transducers (UDPT) that allows the pressure to build up a maximum of $0.5 \mathrm{psi}$ and then releases the gas to keep the pressure constant and the steady state condition.

(E) AIR DRIVEN PUMP WATER SUPPLY (CONFINING AND AXIAL PRESSURE): This pump is used to pressurize the injected water to a maximum of 10.000 psi of confining pressure and axial pressure as well. This confining pressure is going to be connected to a transducer which records pressure with an accuracy of one psi.

(F) PNEUMATIC VALVE (PV): The electrical valve operates through the Lab view software system. However, both valves maintain the operation process, stabilizes the steady 
operational temperature of the unit, as well as preventing interference with the unit to eliminate any human error.

\subsubsection{T-PPAL WORKING LIMIT PRESSURRE}

In order to build a set of experiments, is important to know the T-PPAL limitations, the following table shows the limitations for different parts of the system.

\begin{tabular}{|c|r|r|}
\hline PART & PRESSURE LIMIT $(p s i)$ & SUGGESTED WORKING PRESSURE (psi) \\
\hline CORE HOLDER & $15,000.00$ & $10,000.00$ \\
\hline UPSTREAM GAS TANK & $2,000.00$ & $1,500.00$ \\
\hline AIR DRIVEN PUMP & $15,000.00$ & $11,250.00$ \\
\hline WATER PIPE 1/8 & $7,000.00$ & $5,250.00$ \\
\hline GAS PIPE 1/8 & $7,000.00$ & $5,250.00$ \\
\hline VALVES & $6,000.00$ & $6,000.00$ \\
\hline
\end{tabular}

Table 1 T-PPAL WORKING LIMIT PRESSURES

According to table 1, although some of the T-PPAL parts go beyond 10.000 psi working pressure, we are limited to the pipe lines that transport the fluid, which in our case the maximum allowable pressure will be 5,250 psi. It is not recommended to go over that value. Since the pipeline is the threshold of the confining/axial stress system, to improve the stress limit, it is suggested to use pipelines with thicker walls or smaller size.

\subsubsection{PERMEABILITY MEASUREMENT}

The permeability of the core sample is measured by introducing a pressure difference across the core sample to allow the gas to flow. Gas flows from the upstream tank through the core sample and then accumulates in the small line on the downstream side of the core holder. This line is connected to an automated bellow valve which is actuated automatically when the pressure difference across the valve reaches a certain value (i.e. set the software for pressure difference across the valve to $0.4 \mathrm{psi}$ ). The pressure difference across the valve is measured with an ultraprecise differential pressure transducer with a maximum limit of 0.5 psi pressure differential. Over time, as the gas accumulates in the downstream line, the pressure difference across the valve increases. Once the pressure difference reaches $90 \%$ of transducer's limit or 0.45 psi, the 
automated bellow valve is actuated by a computer signal. This valve stays open until the pressure in the line equalizes the downstream tank pressure (5 to 10 seconds). The valve is then closed, and the pressure buildup starts over (Zamirian, 2015).

Since the upstream pressure is constant during the test and downstream pressure builds up no more than $0.45 \mathrm{psi}$, the flow rate can be considered under a steady-state condition. The flow rate is then determined based on the difference in the initial and final moles of the gas in the core holder and the downstream line using the measured pressure differential. That allows the flow rates as low as $10^{-6} \mathrm{~cm}^{3} / \mathrm{s}$ to be determined accurately. The data acquisition system records the pressure buildup in the line over time, and the software uses the results to determine the flow rate on real time basis and hence the real time apparent permeability (Eq.1). That would allow the flow to be monitored continuously throughout the experiment and then the sample permeability is determined by Darcy's equation (Zamirian 2015).

$$
k=\frac{2 * \mu * L * V_{L+P} * U D P T_{2}}{A * \Delta t *\left(P_{U}^{2}-\left(P_{D}+U D P T_{2}\right)^{2}\right)}
$$

Where:

K : Permeability of the sample (Darcy)

VL+P : Total volume of the downstream section (V6 to PV) plus the sample pore volume

UDPT2 : Pressure builds up (atm)

$\mu \quad$ : Viscosity (cp)

$\mathrm{L} \quad$ : Length of the of the core sample $(\mathrm{cm})$

A : Cross section area of the plug $\left(\mathrm{cm}^{2}\right)$

$P_{D} \quad$ : Down-stream absolute pressure (atm)

$P_{U} \quad$ : Up-stream absolute pressure (atm)

$\Delta \mathrm{T} \quad$ : Time (sec) 


\subsubsection{STEADY-STATE FLOW RATE VALIDATION}

Since quantification of rock petrophysical properties in shale reservoirs still a challenge, the in situ conditions are critical to obtain accurate results in the measurements, this condition is achieved by maintaining isothermal conditions and the application of the confining stress on the core sample.

It's important to notice, that it's not practical to measure the permeability of shale samples under steady state conditions due to extremely low flow rates and the length of time required for stablish steady state conditions. To determine permeability under state steady conditions, we have to use Darcy's Equation and keep the differential pressure between the two sides of the core and flow rate within the core constant. In other words, in order to reach the steady state condition, the core sample should have a stabilized flow rate, and has to be $100 \%$ saturated with the gas that it's been injected through it. The pressure drop across the sample staying constant over time is a one-dimensional steady-state condition based on Darcy's law (Tarek, 2010). The PPAL system has two one-gallon tanks that act as gas storage, connected to the upstream and downstream end of the core which injects the fluid at a steady level maintaining the pressure constant through the core. The downstream end of the core is connected to an Ultra-precise differential-pressure transducers (UDPT) that allows the pressure to build up a maximum of 0.5 psi and then releases the gas to keep the pressure constant and the steady state condition. Darcy's law is valid when the flow is linear (Darcy, 1856). Hence, the linear pressure builds up at ultra-differential pressure transducer indicates a linear flow of gas through the sample which permits us to apply Darcy's law to calculate the permeability.

$$
q=\frac{q}{A}=\frac{k}{\mu} *\left(\frac{P_{i}-P_{O}}{L}\right)
$$




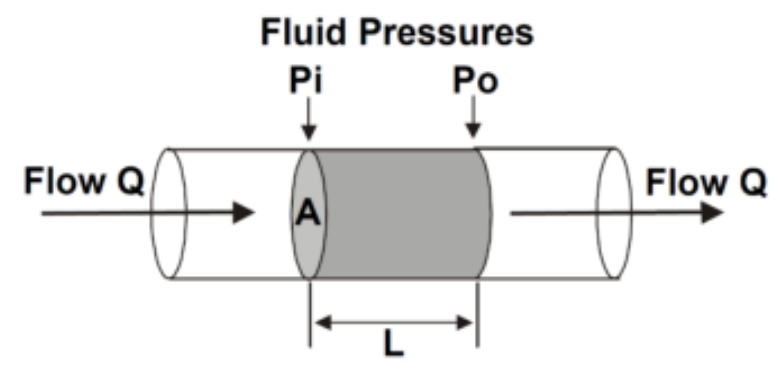

Figure 7 DARCY'S LAW REPRESENTATION

Where:

q : Flow rate $\left(\mathrm{cm}^{3}\right.$ or $\left.\mathrm{m}^{3}\right)$

Po : Outlet fluid pressure (dynes $/ \mathrm{cm}^{2}$ or $\mathrm{Pa}$ )

$\mathrm{Pi} \quad$ : Inlet fluid pressure $\left(\right.$ dynes $/ \mathrm{cm}^{2}$ or $\left.\mathrm{Pa}\right)$

$\mu \quad$ : Dynamic viscosity of the fluid (Poise or $\mathrm{Pa}$ )

$\mathrm{L} \quad$ : Length of the core sample ( $\mathrm{cm}$ or $\mathrm{m}$ )

$\mathrm{K} \quad$ : Permeability of the sample (darcy)

A : Area of the core sample $\left(\mathrm{cm}^{2}\right.$ or $\left.\mathrm{m}^{2}\right)$

\subsubsection{KLINKENBERG CORRECTION}

When the permeability of a rock sample is measured by flow of a gas, the measured permeability values increase as the gas pressure decrease because of the gas slippage effect. Laboratory procedures for isothermal gas permeation lead to higher apparent permeability for porous samples. Explanation for this behavior was given by Klinkenberg in the 1940s in his seminal work that takes into account the phenomena of gas slippage (Klinkenberg, 1941). Accordingly, the steady-state flow rate through small capillaries is higher due to slippage of gas molecules by the capillary walls. In addition to the capillary size the slip is dependent on the type of permeating gas and the pore pressure; consequently, the measured permeability values for the sample could vary significantly. The Klinkenberg slip theory also yields a widely-known graphical technique that displays the measured permeability variations with respect to the reciprocal of the average pore pressure as a straight-line with an intercept equal to the absolute permeability of the sample and 
a slope related to mean free path of the gas molecules, (Klinkenberg, 1941). The following equation shows the Klinkenberg slip theory:

$$
K_{a}=k *\left(1+\frac{b}{p}\right)
$$

Where:

Ka : Apparent permeability.

$\mathrm{K}$ : Liquid permeability.

B : The slope of Klinkenberg straight line.

P : Pore pressure.

\subsubsection{DOUBLE SLIPPAGE CORRECTION}

Klinkenberg equation was validated using samples in the order of milli-darcy, however this theory fails in samples with permeability in the nano-darcy range Klinkenberg theory considers the momentum carried by the gas molecules hitting the pore walls, gas slippage, which results in higher rates. However, it ignores the momentum that gas molecules can carry to the bulk fluid. Fathi et al (2012) incorporated the momentum carried by bouncing back molecules that lead to a linear relation between permeability and reciprocal of pressure-squared, this is referred to as the double slippage correction as follow:

$$
K_{a}=k *\left(1+\left(\frac{b}{p}\right)^{2} * \frac{L_{k e}}{\lambda}\right)
$$

Where Lke is a length scale associated with the kinetic energy of the bouncing-back molecules. The double-slippage effect can lead to measured permeability values that are even higher than those predicted by Klinkenberg theory at low pressures. Others have observed this phenomenon where the higher gas flow was inadvertently attributed to turbulent flow in nano-pores at low pressures (Rushing, 2004), while the impact of the turbulent flow in shale due to a very low Reynolds number is negligible as compared to gas slippage effects at low pressures (Wu, 1998). 


\subsubsection{EFFECT OF STRESS ON PERMEABILITY}

Stress dependent permeability is influenced by various factors such as overburden stress, minimum and maximum horizontal stress. The weight of overburden formations make the target zone subject to high stress. In general, stress can be defined in terms of magnitudes and directions using the Cartesian axes, the vertical axe that acts as the vertical stress $\delta_{v}$ and two perpendicular horizontal axes that act as the maximum $\delta_{H}$ and minimum $\delta_{h}$ horizontal stress as shown in figure 1.

\subsubsection{VERTICAL STRESS $\delta_{v}$}

Also referred to overburden stress, is the sum of all the pressures applied by all the different rock layers. An underground formation has to carry the weight of the overlying formations. The stress at the bottom of a homogeneous column of z is $\delta_{v}=\rho * g * z, \rho$ is the bulk density of the rock above. If the density varies with depth, the vertical stress at depth $D$ becomes:

$$
\delta_{v}=\int_{0}^{D} \rho(z) * g d z
$$

Alternatively, an approximated vertical stress can be calculated using the equation (6):

$$
\delta_{v}=\frac{\rho * T V D}{144}
$$

Where:

$\delta_{v} \quad$ : Vertical stress.

$\rho \quad$ : Average density of the formations above the target reservoir $(\mathrm{lb} / \mathrm{ft} 3)$.

TVD : True vertical depth of the target reservoir $(f t)$.

144 : Conversion factor from $f t^{2}$ to inches $^{2}$.

\subsubsection{MINIMUM HORIZONTAL STRESS $\delta_{h}$}

Minimum horizontal stress is basically regarded as fracture closure pressure. Minimum horizontal stress or fracture closure pressure can be obtained from either DFIT (diagnostic fracture injection test) or by using the following equation (if rock properties are available): 


$$
\delta_{h}=\left(\frac{v}{1-v}\right) *\left(\delta_{V}-P_{p}\right)+P_{p}
$$

Where:

$\delta_{h} \quad$ : Minimum horizontal stress.

$v$ : Poisson's Ratio.

$\delta_{v} \quad$ : Vertical stress.

$P_{p}$ : Pore Pressure.

Equation 7, is based on the assumption of isotropic rock and no tectonic stress. For anisotropic rock and considering tectonic stress, more complicated equation is established. (Far et al., 2015, Murphy et al., 2015).

\subsubsection{MAXIMUM HORIZONTAL STRESS $\delta_{H}$}

Maximum horizontal stress is more challenging to calculate because it cannot be measured directly. One simple technique of using open-hole hydraulic fracturing in vertical well is used to determine the orientation and magnitude of the maximum horizontal stress as follows:

$$
\delta_{H}=3 * \delta_{h}-P_{b}-P_{p}+T_{0} \quad \text { Eq. } 8
$$

Where:

$\delta_{H} \quad$ : Maximum horizontal stress.

$\delta_{h} \quad$ : Minimum horizontal stress.

$P_{b} \quad$ : Breakdown Pressure.

$T_{o} \quad$ : Tensile Stress. 


\section{CHAPTER 3: METHODOLOGY}

For this study, the T-PPAL will be used to test the influence of stress in permeability in two cases, the first case, is to study the vertical permeability simulating in-situ stress state $\left(\sigma_{v}>\sigma_{h}\right)$ in a vertically drilled core sample, the second case is to study the horizontal permeability under different horizontal stress anisotropy in a horizontally drilled core sample. Because T-PPAL system allows for analysis of independent magnitudes of overburden pressure and axial pressure, it most accurately represents the anisotropy found in the shale formation.

During this semester, work has been done in the lab to hook up some parts to the T-PPAL system. Currently, to start performing experiments, , a Carbon Dioxide $\left(\mathrm{CO}_{2}\right)$ gas regulator, a $\mathrm{Helium}\left(\mathrm{H}_{2}\right)$ gas regulator are needed in order to connect the air and gas lines to the T-PPAL system. Then, the software needs to be tested to make sure all the valves are working well.

The work done and the parts that were hooked up are described below:

$>$ Ordered Air tank, Helium tank and Carbon dioxide tank.

Water line hose to the air driven pump.

Air driven pump to the air tank.

$>$ Connections between the gas boosters to the air tank and the gas upstream pressure.

\subsection{METHODOLOGY TO MEASURE PERMEABILITY WITH EQUAL CONFINING AND AXIAL PRESSURE (PPAL)}

In order to develop the methodology to test the anisotropy permeability under in-situ stress condition using the T-PPAL system, a set of experiments performed by Zamirian et al., 2015 are introduced to understand the procedure to determine the effect of stress in permeability (geomechanical effect) with equal confining and axial stress magnitude.

Permeability are performed setting increasingly ranges of confining and average gas pore pressure at a constant net confining pressure. After the pressure difference and flow rate results 
are measured from the test, the next step is to calculate the apparent permeability based on Darcy's law. Next, the intrinsic permeability can be determined by fitting to the data to either Klinkenberg or double slippage model in order to study the pore pressure effect. Finally, the previous steps of measuring kap will be repeated under different constant net confining stresses from low to high to study the geomechanical effect on permeability.

When the permeability of a rock sample is measured by flow of a gas, the measured permeability values increase as the gas pressure decrease because of the gas slippage effect. (Klinkenberg 1941) demonstrated that the permeability of porous media to gases is a linear function of the reciprocal pressure. His theory suggests that the momentum carried by the gas molecules hitting the pore walls, gas slippage, results in higher gas velocities. For shales which have average pore sizes smaller than $10 \mathrm{~nm}$ (Akkutlu and Fathi 2011, Adesida et. al, 2011), the Klinkenberg theory is not valid because it ignores the momentum that gas molecules can carry to the bulk fluid. Fathi et al (2012) incorporated the momentum carried by bouncing back molecules that lead to a linear relation between permeability and reciprocal of the square of pressure. This is referred as the double slippage correction or Klinkenberg correction. Double slippage effect has to be applied to the permeability measurements and the intersection between the slope and the $Y$ axis of the linear function will be the intrinsic or absolute permeability. The slope and intersect should be function of net confining stress. Figure 8 illustrates results of apparent permeability (Zamirian et al 2015) measured at different pore pressures under nine different constant net confining stresses. In the same figure, the data is fit to the double slippage model for each net confining stress. Based on Fig. 8, the slopes and intersects (intrinsic permeability $k_{\text {int }}$ ) of the fitting model are plotted against to the net confining stress to illustrate the geomechanical effect on permeability (Fig. 9). 


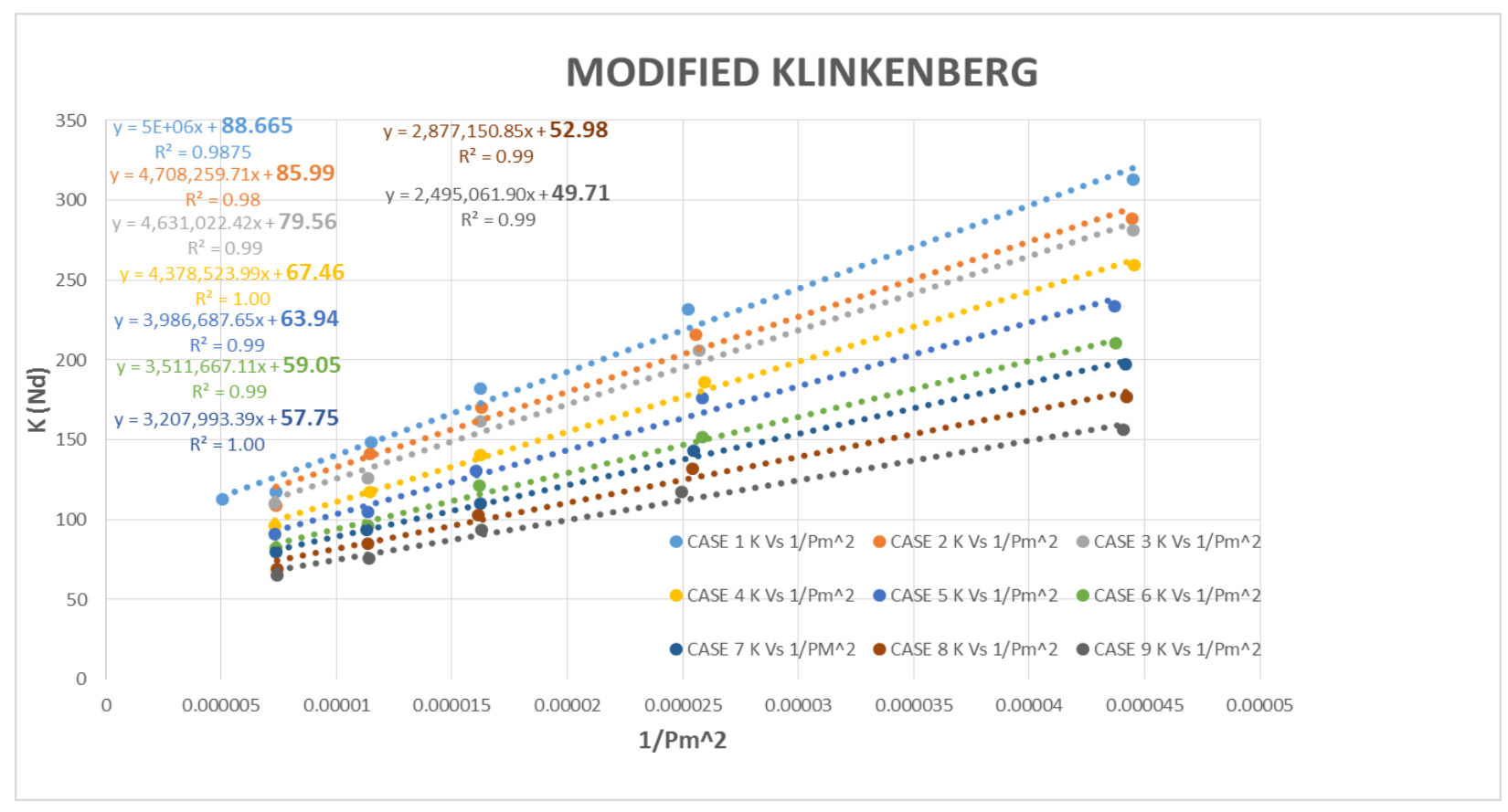

Figure 8 ABSOLUTE PERMEABILITY VS PORE PRESSURE EFFECT (MODIFIED FROM ZAMIRIAN ET AL., 2015)

\begin{tabular}{|c|c|}
\hline $\begin{array}{c}|c| \\
\text { EFFECT OF NET PRESSURE } \\
\text { OVER INTRINSIC } \\
\text { PERMEABILITY }\end{array}$ \\
\hline Kint & Pnet \\
\hline 88.66 & 585 \\
\hline 85.98 & 1121 \\
\hline 79.56 & 1657 \\
\hline 67.46 & 2227 \\
\hline 63.94 & 2950 \\
\hline 59.05 & 3640 \\
\hline 57.75 & 4559 \\
\hline 52.97 & 5454 \\
\hline 49.71 & 6463 \\
\hline
\end{tabular}

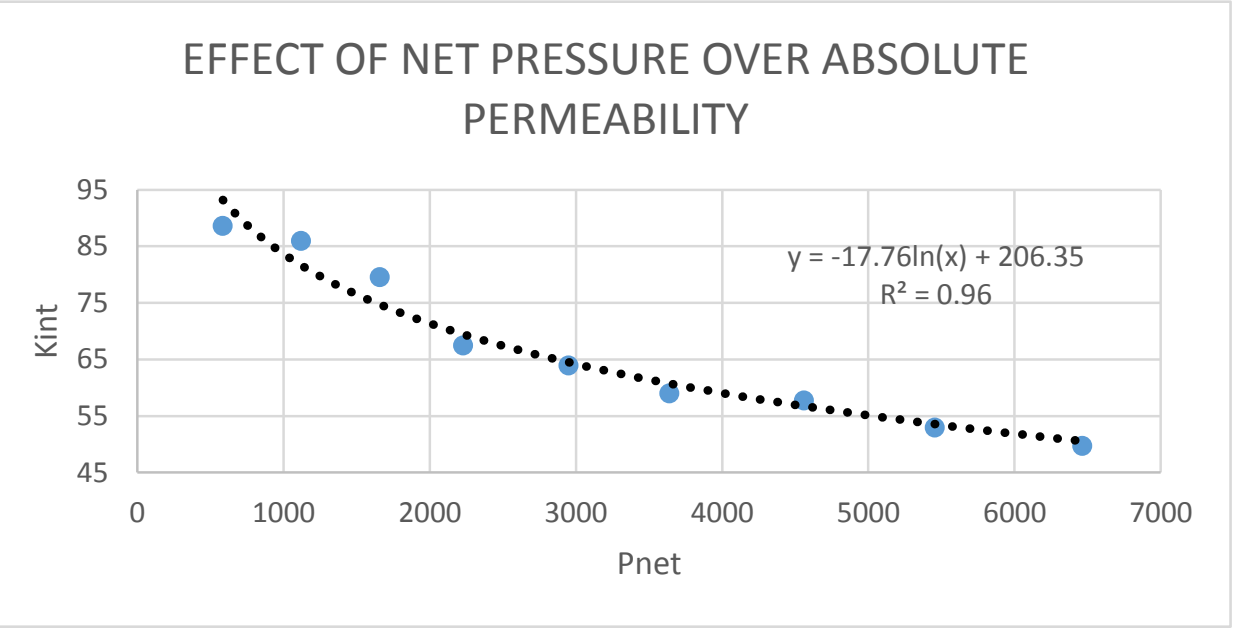

Table 2 Kint AND Pnet DATA Figure 9 EFFECT OF NET STRESS IN ABSOLUTE PERMEABILITY MODIFIED FROM ZAMIRIAN ET AL., 2015) 


\begin{tabular}{|c|c|}
\hline $\begin{array}{c}\text { EFFECT OF NET PRESSURE } \\
\text { OVER Slope }\end{array}$ \\
\hline Slope & Pnet \\
\hline $5,21 \mathrm{E}+00$ & 585 \\
\hline 4,71 & 1121 \\
\hline 4,63 & 1657 \\
\hline 4,38 & 2227 \\
\hline 3,99 & 2950 \\
\hline 3,51 & 3640 \\
\hline 3,21 & 4559 \\
\hline 2,88 & 5454 \\
\hline 2,5 & 6463 \\
\hline
\end{tabular}

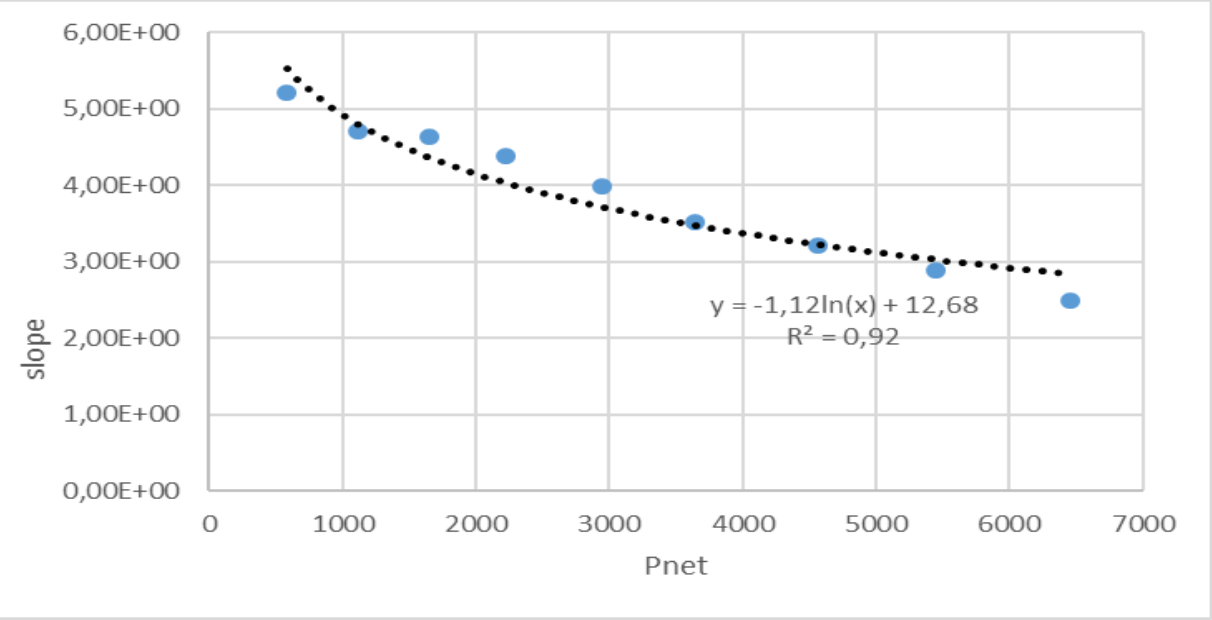

Table 3 SLOPE AND Pnet DATA Figure 10 GEOMECHANICAL EFFECT ON PERMEABILITY MODIFIED FROM ZAMIRIAN ET AL., 2015)

Based on the plots shown in figure 9 and figure 10, the following equation describes the effect of both pore pressure and geomechanic in permeability.

$$
K_{\text {app }}=\operatorname{slope}\left(P_{\text {net }}\right) * \frac{1}{P_{\text {meanpore }}^{2}}+\operatorname{int}\left(P_{\text {net }}\right)=\left(1.12 \ln \left(P_{\text {net }}\right)+12.68\right) * \frac{1}{P_{\text {meanpore }}^{2}}+17.76 \ln \left(P_{\text {net }}\right)+206.35
$$

Eq. 9

\subsection{TRI-AXIAL METHODOLOGY}

Previous work such as Zamirian et al 2015, tested the effect of stress in permeability under steady-state condition using the PPAL System. Permeability of the sample is measured at equal confining and axial stress magnitudes at different pore pressures keeping the net pressure constant. Even though the PPAL system gives accurate permeability measurements with good repeatability, it cannot study the stress anisotropy effect on permeability test with non-equal axial and confining stress condition. To overcome these limitations a new methodology (T-PPAL) is proposed to test shale core permeability under in-situ stress state, following Zamirian et al 2015 methodology. 
To determine the effect of stress anisotropy in permeability under in-situ stress state, the methodology used by Zamirian et al 2015 , is followed by applying different ratios of axial to confining stress to the core samples. Unlike Zamirian et al., 2015 experiment, apparent permeability will be measured at different anisotropy ratios (independent confining and axial magnitudes), while a pressure difference is set to make the gas flow through the core keeping the confining and horizontal net pressure constant. An experiment consisting in several runs of different average gas pressures and different anisotropy ratios will be done. Absolute permeability then, can be determined by using Klinkenberg or double slippage correction.

\subsubsection{T-PPAL TEST PROCEDURE}

Preparing a broad and precise set of experiments to measure the effect of stress anisotropy in permeability requires different tests, using different gases at different stress conditions, therefore it is important to have a detailed procedure to avoid damages to the plug sample during the experiments and to minimize the time needed to perform the tests.

One technical step to be followed before any test starts is to check for leakage throughout the entire system, along the connections, gas pipe lines among others. To perform the leakage test, a blank core has to be used and each section has to be tested separately, that way if there is any leakage is easier to find. A leakage test ought to be done every time the core holder is opened, since joint and valves connected to the core holder are subject to stress each time a core sample is loaded. Regarding the sections that are not connected to the core holder just one leakage test is enough. If no leakage is found, proceed the stepwise procedure to run a full set of experiments on a core sample, presented below.

1. Dry the core plug in humidity oven to the condition that is needed according to the core plug sample until its weight stabilizes. This process removes all the free water except one or two layers of water on the clays. This prevents the minerals deformation due to drying (Busch 1970, Soeder 1988). 
2. Load a blank sample in the core holder and apply the 500 psia confining and axial pressure. This pressure preserves the sample from geomechanical changes due to net stress effects. It will also reveal any possible problem with the water leak from the gas lines. If no water leak is observed, then the core holder can be connected to the gas system.

3. Pressurize the system to 200 psia gas pressure.

4. Isolate T-PPAL from room, and set the temperature and monitor the temperature until the system temperature reaches the set value. It may take up to 72 hours for the temperature to stabilize depending on the temperature of the water used for confining pressure.

5. Isolate all the T-PPAL gas sections by closing all the valves, and monitor the pressure over time to detect any gas leakage.

6. Repair or replace the leaking sections and repeat the monitoring until no gas leakage is observed in the whole system.

7. Apply axial pressure based on the anisotropy designed. For example, if anisotropy ratio $\gamma_{1}$ is selected, axial pressure is set to be $\sigma_{\text {axial }}{ }^{\prime}=\sigma_{\text {conf }}{ }^{*} \gamma_{1}$

8. Set the upstream and downstream pressure to 150 and 50 psia respectively and perform permeability tests. Permeability tests depending on the permeability, TOC of the sample and the type of gas might take few minutes to couple of hours. It is recommended that the permeability test be repeated at least 30 times to determine if the results are reliable and the sample is completely saturated (adsorbed/desorbed).

9. Increase the upstream and downstream pressures for the next set of measurements. During these measurements, as the gas pressure is increased, the confining and axial pressure should be increased such that the confining and axial net stress remain constant, The main purpose here is to measure the effect of gas type and its pressure on permeability. When an adsorbent gas such as Carbon Dioxide or methane is used, the pore volume changes due to the adsorbed layer thickness at pressures above 3,000 psia (Santos, 2012). 
10. Repeat the permeability test for at least four different mean gas pressures by increasing the pressure from 100 to 400 psia. This will provide enough data for application of the gas slippage correction.

11. Measure the permeability at a low net stress and repeat the measurement steps 7-10 by increasing the net confining stress in 1000 psia increment up to the limit of the system. The axial stress is increased by $1000 * \gamma_{1}$

12. Change the anisotropy ratio based on the proposed template (table 4) to $\gamma_{2}, \gamma_{3}$, until the last anisotropy ratio is reached. The steps 7-12 are repeated to study the stress anisotropy effect on permeability.

Steps 1 to 6 are pre-test for leakage testing (Zamirian et al., 2015), and steps 7 to 12 are the formal T-PPAL test for permeability testing. 
Table 4 presented below, represents a template that was designed to do the calculations to determine the effect of stress anisotropy in permeability.

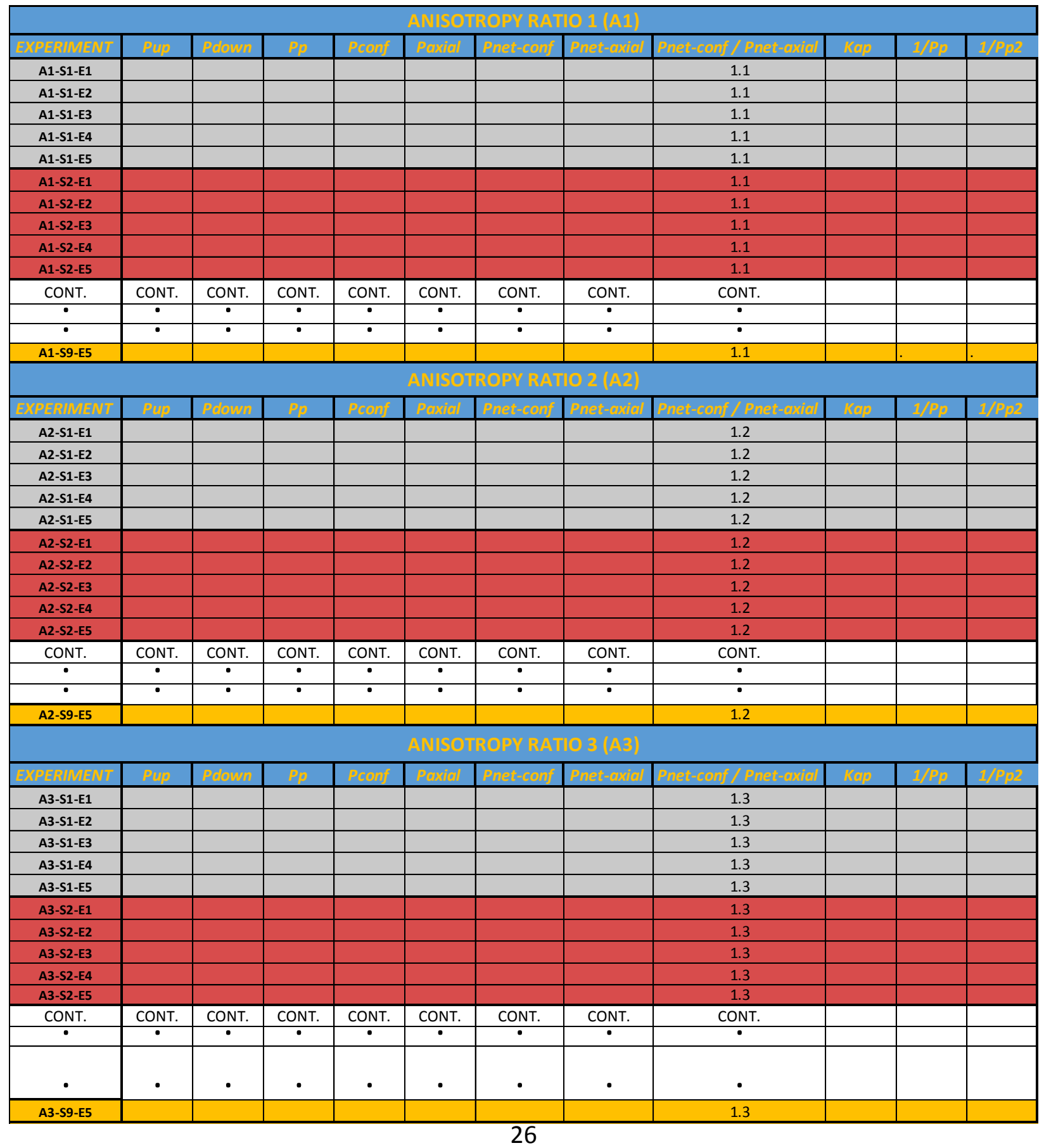


Each run is classified under the following nomenclature, $A \#-S \#-E \#$, where $A \#$ is the anisotropy ratio, $\mathrm{S \#}$ is the net confining stress and $\mathrm{E \#}$ is the average gas pore pressure. Each color in the template represents a different confining pressure at which the sample is subject and is divided in five runs which represents the five different pore pressure conditions. Table 4 shown above, study the $\mathbf{x}$ number of anisotropy ratios under $\mathbf{Y}$ number of net confining stress conditions. For each stress states, $\mathbf{z}$ number of mean pore pressure cases are conducted. Based on the designed data table, total test number is $\mathbf{X}^{*} \mathbf{Y}^{*} \mathbf{Z}$.

Thanks to recent hardware developments in high precision pressure measurement and data acquisition technology the software that is connected to the T-PPAL system will record several pressure values for further calculations. Once the set of experiments are done, the data gathered from the software can be plugged into the proposed template to proceed and calculate the effect of stress anisotropy in permeability for each anisotropy ratio.

Following, the calculations needed are described:

\subsubsection{Average gas pore pressure:}

$$
P_{p}=\frac{P_{u p}+P_{\text {down }}}{2}
$$

Where:

$$
\begin{aligned}
& \text { Pp : Average gas pore pressure. } \\
& \text { Pup : Gas upstream pressure. } \\
& \text { Pdown : Downstream pressure. }
\end{aligned}
$$

\subsubsection{Stress Anisotropy ratio $\mathrm{\gamma}$ :}

$$
\gamma=\frac{\sigma_{\text {axial }}^{\prime}}{\sigma_{\text {conf }}^{\prime}}
$$

Where:

$$
\sigma_{\text {axial }}^{\prime}: \text { Net Axial pressure }
$$




$$
\sigma_{\text {conf }}^{\prime} \quad \text { : Net Confining radial pressure }
$$

\subsubsection{Effective Confining Pressure}

Where:

$$
\sigma_{\text {conf }}^{\prime}=\sigma_{\text {conf }}-P_{p}
$$

$$
\begin{array}{ll}
\sigma_{\text {conf }}^{\prime} & : \text { Effective Confining Pressure } \\
\sigma_{\text {conf }} & : \text { Confining Pressure } \\
\mathrm{Pp} & : \text { Average gas pore pressure. }
\end{array}
$$

\subsubsection{Effective Axial Pressure}

Where:

$$
\sigma_{\text {axial }}^{\prime}=\sigma_{\text {axial }}-P_{p}
$$

$$
\begin{array}{ll}
\sigma_{\text {axial }}^{\prime} & : \text { Effective axial Pressure } \\
\sigma_{\text {axial }} & : \text { Axial Pressure } \\
\mathrm{Pp} & : \text { Average gas pore pressure. }
\end{array}
$$

Once we have finished the experiments and calculations the next steps, are to determine the absolute permeability applying Klinkenberg or double slippage correction and also to develop an empirical equation of apparent permeability by considering pore pressure effect, geomechanical effect, and stress anisotropy effect can be obtained.

$$
K_{\text {app }}=\operatorname{slope}\left(\sigma_{\text {conf }}^{\prime}, \gamma\right) * \frac{1}{P_{\text {meanpore }}^{2}}+\operatorname{intersection}\left(\sigma_{\text {conf }}^{\prime}, \gamma\right)
$$

Where:

$$
\begin{array}{ll}
\sigma_{\text {conf }}^{\prime} & : \text { Effective Confining Pressure } \\
\sigma_{\text {conf }} & : \text { Confining Pressure } \\
P_{\text {meanpore }}^{2} & : \text { Average gas pore pressure. } \\
\text { Intersection } & : \text { Absolute Permeability. }
\end{array}
$$


With the equation above, a sensitivity study can be conducted to understand the significance of pore pressure effect, geomechanical effect, and the stress anisotropy effect on permeability. The equation can also be used in reservoir simulator to develop a complex reservoir flow model considering the three mechanisms mentioned above.

\subsection{PROPOSED CASE}

The T-PPAL system is applied to study two scenarios:

1. Vertical permeability under certain vertical (axial)/ horizontal (confining) stress ratios.

2. Horizontal permeability under different horizontal stress anisotropy.

The scenario 1 and 2 are designed based upon two different core plug orientations, vertically drilled and horizontally drilled orientations, respectively. It is important to highlight, that the scenarios proposed in each case were prepared taking in account the T-PPAL working limits shown in table 1.

\subsubsection{CASE 1 VERTICALLY DRILLED CORE SAMPLE}

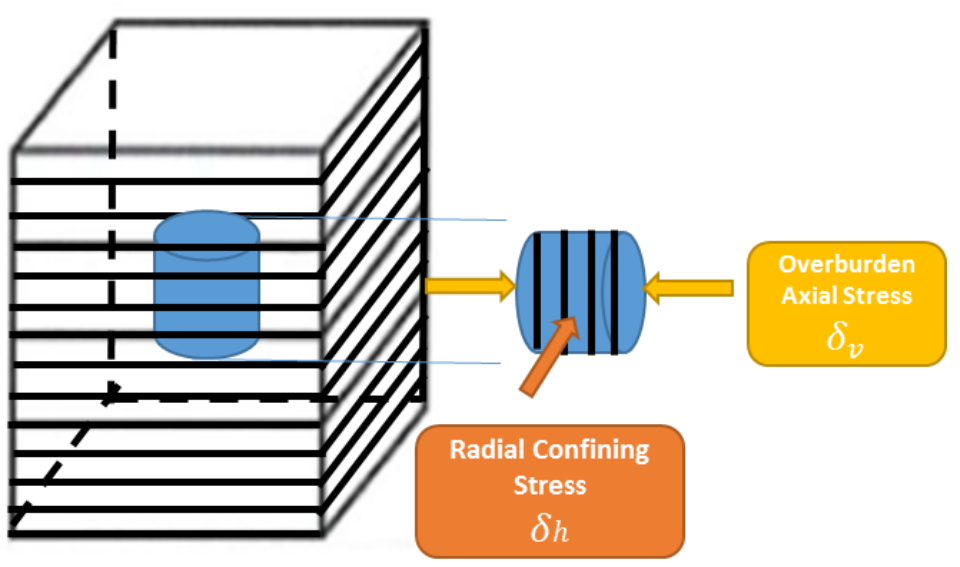

Figure 11 VERTICAL DRILLED CORE SAMPLE 
The target in this case, is to study the effect of anisotropy between the vertical and horizontal stress on vertical permeability, as it can be appreciated in figure 10, the overburden stress $\delta_{v}$ act as the axial stress which in this case is larger than the radial confining stress. They usually follow the relationship shown in equation 7. The Confining stress is approximated to the vertical stress since the core geometry is cylindrical, the confining stress is an average between maximum and minimum horizontal stress. Figure 11 represent the relationship between vertical and horizontal stresses.
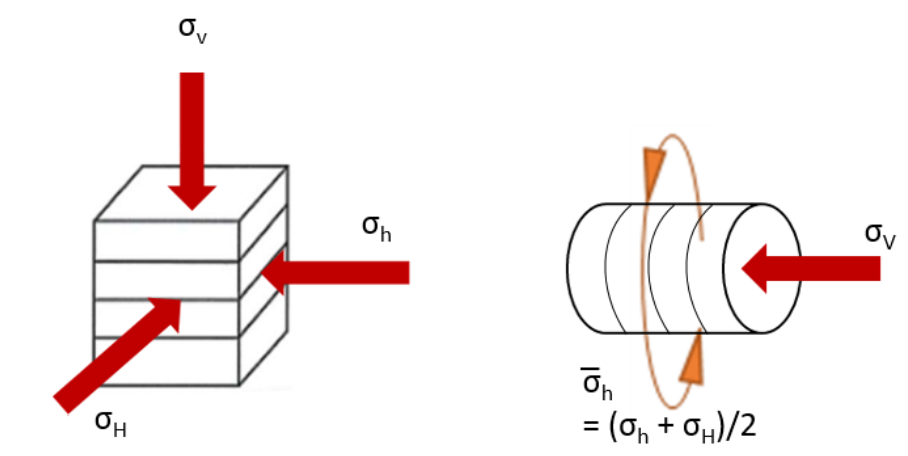

Figure 12 VERTICAL AND HORIZONTAL STRESS RELATIONSHIP

To find the relationship between effective vertical and horizontal stress, equation 7 has to be derived, as follows:

$$
\frac{\sigma^{\prime} v}{\sigma^{\prime} h}=\left(\frac{1-v}{v}\right)
$$

Where:

$$
\begin{array}{ll}
\frac{\sigma^{\prime} v}{\sigma^{\prime} h} & : \text { Anisotropy ratio } \\
v & : \text { Poisson's Ratio. }
\end{array}
$$

Shale Poison's ratio values usually ranges from 0.1 to 0.5 , based on the Poisson's ratio range using equation 12 and the stress limit of the system, the following anisotropy ratios can be designed. An increment of 0,5 will be used along the Poisson's ratio ranges. 


\begin{tabular}{|c|c|}
\hline $\boldsymbol{v}$ & $\boldsymbol{\delta}^{\prime}{ }_{\boldsymbol{v}} / \boldsymbol{\delta}_{\boldsymbol{h}}$ \\
\hline 0.5 & 1 \\
\hline 0.45 & 1.22 \\
\hline 0.4 & 1.50 \\
\hline 0.35 & 1.86 \\
\hline 0.3 & 2.33 \\
\hline 0.25 & 3 \\
\hline 0.2 & 4 \\
\hline \multicolumn{2}{|c|}{ Table 5 ANISOTROPY RATIO CALCULATIONS }
\end{tabular}

Following, is presented the proposed scenarios to study the effect of anisotropy stress permeability.

\begin{tabular}{|r|c|r|}
\hline \multicolumn{3}{|c|}{ SCENARIO 1 } \\
\hline RATIO & Pnet conf & Pnet axial \\
\hline 1.00 & 1000 & $1,000.00$ \\
\hline 1.22 & 1000 & $1,222.22$ \\
\hline 1.50 & 1000 & $1,500.00$ \\
\hline 1.86 & 1000 & $1,857.14$ \\
\hline 2.33 & 1000 & $2,333.33$ \\
\hline 3.00 & 1000 & $3,000.00$ \\
\hline 4.00 & 1000 & $4,000.00$ \\
\hline
\end{tabular}

\begin{tabular}{|r|c|c|}
\hline \multicolumn{3}{|c|}{ SCENARIO 2 } \\
\hline RATIO & Pnet conf & Pnet axial \\
\hline 1.00 & 2000 & $2,000.00$ \\
\hline 1.22 & 2000 & $2,444.44$ \\
\hline 1.50 & 2000 & $3,000.00$ \\
\hline 1.86 & 2000 & $3,714.29$ \\
\hline 2.33 & 2000 & $4,666.67$ \\
\hline 3.00 & 2000 & 6000 \\
\hline 4.00 & 2000 & 8000 \\
\hline
\end{tabular}

\begin{tabular}{|r|c|r|}
\hline \multicolumn{3}{|c|}{ SCENARIO 3 } \\
\hline RATIO & Pnet conf & Pnet axial \\
\hline 1.00 & 3000 & $3,000.00$ \\
\hline 1.22 & 3000 & $3,666.67$ \\
\hline 1.50 & 3000 & $4,500.00$ \\
\hline 1.86 & 3000 & $5,571.43$ \\
\hline 2.33 & 3000 & $7,000.00$ \\
\hline 3.00 & 3000 & $9,000.00$ \\
\hline 4.00 & 3000 & $12,000.00$ \\
\hline
\end{tabular}

Table 6 PROPOSED CASE FOR VERTICAL DRILLED CORE SAMPLE

Relative to the T-PPAL working limits (table 1), for scenario 2 is not possible to go beyond the anisotropy ratio of 2.33 and for scenario 3 clearly, is noticed that the maximum allowed anisotropy ratio is 1.50 .

According to table 6 , the total number of stress states are $3 * 7-6=15$. For case 1 , assuming 5 mean pore pressures are conducted for each stress state, the total number of permeability tests will be $15 * 5=75$. Through the test, the empirical correlation of vertical permeability as a function of overburden stress and overburden/horizontal stress ratio is obtained:

$$
K_{\text {Vapp }}=\operatorname{slope}\left(\sigma_{\text {overburden }}^{\prime} \gamma\right) * \frac{1}{P_{\text {meanpore }}^{2}}+\operatorname{int}\left(\sigma_{\text {overburden }}^{\prime}, \gamma\right)
$$

Where the stress anisotropy ratio $\gamma$ here is the overburden to average horizontal stress ratio. 


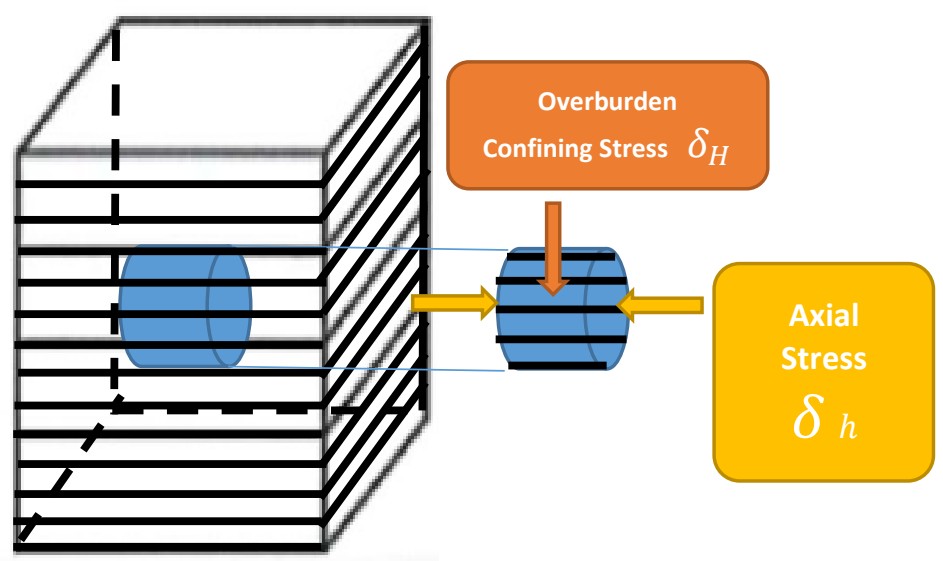

Figure 13 HORIZONTAL DRILLED CORE SAMPLE

The target in this case, is to study the effect of anisotropy between the two orthogonal horizontal stresses on horizontal permeability, as it can be appreciated in figure 13, one horizontal stress $\delta_{H}$ act as the radial confining stress which in this case is larger than the horizontal stress at the orthogonal direction-axial minimum horizontal stress $\delta_{h}$. Commonly, hydraulic fractures are vertical, perpendicular to the minimum horizontal stress because the overburden is the largest principle stress. Hence, it is the horizontal permeability which contributes more to the gas flow. In this case it is assumed that the confining stress represents one horizontal stress, and the axial is another horizontal stress. It should be kept in mind that since the core geometry is cylindrical, the actual radial stress is a function of azimuth, $\sigma_{v}$ and $\sigma_{H}\left(\sigma_{v}>\sigma_{H}\right)$, which is $\geq \sigma_{h}$., figure 12 represent the relationship between vertical and horizontal stresses.
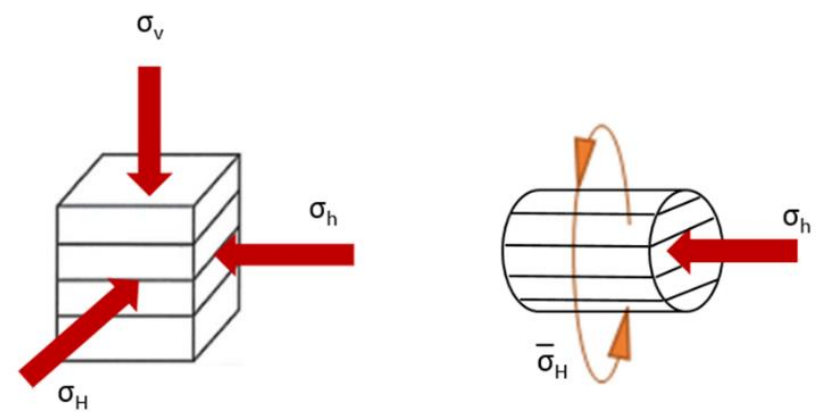

Figure 14 VERTICAL AND HORIZONTAL STRESS RELATIONSHIP 
Confining pressures are fixed changing axial stress to make different stress ratios (different horizontal stress anisotropy). Different sets of stress anisotropy ratio used for this case is as follow:

\begin{tabular}{|c|}
\hline $\boldsymbol{\delta}^{\prime}{ }_{\boldsymbol{h}} / \boldsymbol{\delta}_{\boldsymbol{H}}$ \\
\hline $1 / 1.5=0.67$ \\
\hline $1 / 1.4=0.71$ \\
\hline $1 / 1.3=0.77$ \\
\hline $1 / 1.2=0.83$ \\
\hline $1 / 1.1=0.91$ \\
\hline
\end{tabular}

Following, is presented the proposed scenarios to study the effect of anisotropy stress

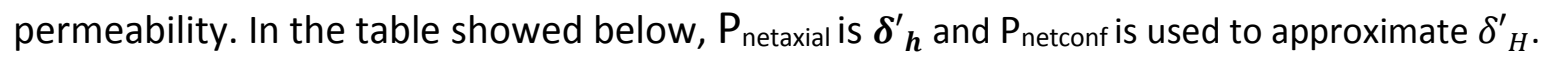

\begin{tabular}{|r|c|r|}
\hline \multicolumn{3}{|c|}{ SCENARIO 1 } \\
\hline RATIO & Pnet conf & Pnet axial \\
\hline 0.67 & 1000 & 666.67 \\
\hline 0.71 & 1000 & 714.29 \\
\hline 0.77 & 1000 & 769.23 \\
\hline 0.83 & 1000 & 833.33 \\
\hline 0.91 & 1000 & 909.09 \\
\hline
\end{tabular}

\begin{tabular}{|r|c|r|}
\hline \multicolumn{3}{|c|}{ SCENARIO 2 } \\
\hline RATIO & Pnet conf & Pnet axial \\
\hline 0.67 & 2000 & $1,333.33$ \\
\hline 0.71 & 2000 & $1,428.57$ \\
\hline 0.77 & 2000 & $1,538.46$ \\
\hline 0.83 & 2000 & $1,666.67$ \\
\hline 0.91 & 2000 & $1,818.18$ \\
\hline
\end{tabular}

\begin{tabular}{|r|c|r|}
\hline \multicolumn{3}{|c|}{ SCENARIO 3 } \\
\hline RATIO & Pnet conf & Pnet axial \\
\hline 0.67 & 3000 & $2,000.00$ \\
\hline 0.71 & 3000 & $2,142.86$ \\
\hline 0.77 & 3000 & $2,307.69$ \\
\hline 0.83 & 3000 & $2,500.00$ \\
\hline 0.91 & 3000 & $2,727.27$ \\
\hline
\end{tabular}

\begin{tabular}{|r|c|r|}
\hline \multicolumn{3}{|c|}{ SCENARIO 4 } \\
\hline RATIO & Pnet conf & Pnet axial \\
\hline 0.67 & 4000 & $2,666.67$ \\
\hline 0.71 & 4000 & $2,857.14$ \\
\hline 0.77 & 4000 & $3,076.92$ \\
\hline 0.83 & 4000 & $3,333.33$ \\
\hline 0.91 & 4000 & $3,636.36$ \\
\hline
\end{tabular}

\begin{tabular}{|r|c|r|}
\hline \multicolumn{3}{|c|}{ SCENARIO 5 } \\
\hline RATIO & Pnet conf & Pnet axial \\
\hline 0.67 & 5000 & $3,333.33$ \\
\hline 0.71 & 5000 & $3,571.43$ \\
\hline 0.77 & 5000 & $3,846.15$ \\
\hline 0.83 & 5000 & $4,166.67$ \\
\hline 0.91 & 5000 & $4,545.45$ \\
\hline
\end{tabular}

Table 8 PROPOSED CASE FOR A HORIZONTAL DRILLED CORE SAMPLE

According to the T-PPAL working limit, is not posiblle to perform another scenario beyond 5,000 psia of net confining pressure. Values shown in table 7 are going to be used to perform the 
experiments. After the test, the empirical correlations of horizontal permeability as function of effective horizontal stress and horizontal stress anisotropy can be obtained, as follows:

$$
K_{\text {happ }}=\operatorname{slope}\left({\sigma^{\prime}}_{h}, \gamma\right) * \frac{1}{P_{\text {meanpore }}^{2}}+\operatorname{int}\left({\sigma^{\prime}}_{h}, \gamma\right)
$$

Where the stress anisotropy ratio $\gamma$ here is the min horizontal stress to approximated maximum horizontal stress ratio. 


\section{CHAPTER 4: CONCLUSION}

The main purpose of this research is to study the influence of stress anisotropy (the ratio of the two stresses at two orthogonal directions) on permeability under steady state condition using the T-PPAL system. To achieve this objective a Tri-axial core holder is used to apply axial and confining stress to the core plug independently with different magnitudes. Based on the coring orientation, two tests are designed using T-PPAL system. For case 1, when the core sample is drilled vertically, a test is designed to investigate the effect of vertical-to-horizontal stress ratio on vertical permeability. For case 2 , when the core sample is drilled horizontally, another test is designed to study the effect of horizontal stress anisotropy on horizontal permeability.

The following outcomes were reached upon completion of this study:

A sensitivity study can be conducted to understand the significance of pore pressure effect, geomechanical effect, and the stress anisotropy effect on permeability.

An empirical equation of apparent permeability $\left(k_{\mathrm{ap}}\right)$ considering the three mechanisms mentioned above can be derived and be used in reservoir simulator to develop a complex reservoir flow model.

$>\mathrm{CO}_{2}$ can lead to a TOC swelling causing permanent permeability changes, which may lead to a repeatability issue. Therefore, to study the gas effect, it is suggested to measure non adsorbed gas such as $\mathrm{N}_{2}$ and He before $\mathrm{CO}_{2}$.

$>$ Carbonate and sandstone cases are used for isotropic rock case. But current system is not capable to measure high permeable sandstone. In order to use this type of rock samples, the system has to be modified to measure the sandstone, for example increasing the PV threshold pressure 0.45 psi.

For shale case, the vertical permeability is usually several magnitudes lower than the horizontal permeability. So it can be too low to be measured accurately by the current system. For shale case, it is suggested to study the horizontal stress anisotropy first. 


\section{REFERENCES}

1. Akkutlu, I. Yucel, and Ebrahim Fathi. "Multiscale gas transport in shales with local kerogen heterogeneities." SPE Journal 17.04 (2012): 1-002.

2. Ali, T. A., \& Sheng, J. J. (2015, October 13). Evaluation Of The Effect Of Stress-dependent Permeability On Production Performance in Shale Gas Reservoirs. Society of Petroleum Engineers. doi:10.2118/177299-MS

3. Council, Ground Water Protection. Modern shale gas development in the United States: A primer. na, 2009.

4. Darcy, Henry. Les fontaines publiques de la ville de Dijon: exposition et application... Victor Dalmont, 1856.

5. Elsaig, Mohamed. Characterizations of the Marcellus Shale petrophysical properties. Diss. West Virginia University, 2016.

6. Fan, L., Thompson, J. W., \& Robinson, J. R. (2010, January 1). Understanding Gas Production Mechanism and Effectiveness of Well Stimulation in the Haynesville Shale Through Reservoir Simulation. Society of Petroleum Engineers. doi:10.2118/136696-MS

7. Far, M. E., Buller, D., Quirein, J., Gu, M., \& Gokaraju, D. (2015, August 10). A new Integrated Data Analysis Algorithm and Workflow for Optimizing Horizontal Well Completion in Unconventional Reservoirs. Society of Petrophysicists and Well-Log Analysts.

8. Fathi, E., Tinni, A., \& Akkutlu, I. Y. (2012, January 1). Shale Gas Correction to Klinkenberg Slip Theory. Society of Petroleum Engineers. doi:10.2118/154977-MS

9. Fathi, Ebrahim, Ali Tinni, and I. Yucel Akkutlu. "Correction to Klinkenberg slip theory for gas flow in nano-capillaries." International Journal of Coal Geology 103 (2012): 51-59.

10. Gu, M., Kulkarni, P., Rafiee, M., Ivarrud, E., \& Mohanty, K. (2016, November 1). Optimum Fracture Conductivity for Naturally Fractured Shale and Tight Reservoirs. Society of Petroleum Engineers. doi:10.2118/171648-PA

11. Jones, S. C. "A technique for faster pulse-decay permeability measurements in tight rocks." SPE formation evaluation 12.01 (1997): 19-26.

12. Klinkenberg, L. (1941). The Permeability of Porous Media to Liquid and Gases. API Drilling and Production Practices, 200-213.

13. Murphy, E., Barraza, S. R., Gu, M., Gokaraju, D., Far, M. E., \& Quirein, J. (2015, August 10). New Models for Acoustic Anisotropic Interpretation in Shale. Society of Petrophysicists and Well-Log Analysts.

14. Randolph, P. L. "Porosity and permeability of Mesaverde sandstone core from the US DOE Multiwell Experiment, Garfield County, Colorado." SPE/DOE Low Permeability Gas Reservoirs Symposium. Society of Petroleum Engineers, 1983.

15. Rushing, J. N. (2004). Klinkenberg-Corrected Permeability Measurements in Tight Gas Sands: Steady-State versus Unsteady-State Techniques. Paper SPE 89867 presented at the SPE Annual Technical Conferene. Houston, Texas.

16. Santos, Jose M., and I. Yucel Akkutlu. "Laboratory Measurement of Sorption Isotherm Under Confining Stress With Pore-Volume Effects." Spe Journal 18.05 (2013): 924-931.

17. Soeder, Daniel J. "Porosity and permeability of eastern Devonian gas shale." SPE Formation Evaluation 3.01 (1988): 116-124.

18. Tarek, A. (2010). Darcy's Law. In Reservoir Engineering Handbook (pp. 341-343). Oxford, UK: Gulf Professional Publishing.

19. Tinni, A., Fathi, E., Agarwal, R., Sondergeld, C. H., Akkutlu, I. Y., \& Rai, C. S. (2012, January 1). Shale Permeability Measurements on Plugs and Crushed Samples. Society of Petroleum Engineers. doi:10.2118/162235-MS

20. Wu, Y. P. (1998). Gas Flow in Porous Media with Klinkenberg Effects. Transp. Porous Media , 32, 117-137 
21. Zamirian, M., Aminian, K. K., Ameri, S., \& Fathi, E. (2014, September 30). New Steady-State Technique for Measuring Shale Core Plug Permeability. Society of Petroleum Engineers. doi:10.2118/171613-MS

22. Zamirian, M., Aminian, K., \& Ameri, S. (2015, September 28). Measurement of Key Shale Petrophysical Properties. Society of Petroleum Engineers. doi:10.2118/174968-MS

23. Zamirian, M., Aminian, K., Fathi, E., \& Ameri, S. (2014, October 21). A Fast and Robust Technique for Accurate Measurement of the Organic-rich Shales Characteristics under Steady-State Conditions. Society of Petroleum Engineers. doi:10.2118/171018-MS

24. Zamirian, Mehrdad. New Experimental Approach to Measure Petrophysical Properties of Organic-Rich Shales. WEST VIRGINIA UNIVERSITY, 2015. 